\title{
Interannual Variability of the Mixed Layer Winter Convection and Spice Injection in the Eastern Subtropical North Atlantic
}

\author{
Nicolas KolodZiejcZyK, Gilles Reverdin, AND Alban LAZAR \\ LOCEAN Laboratory, Sorbonne Universités (UPMC, University of Paris 6)-CNRS-IRD-MNHN, Paris, France
}

(Manuscript received 7 March 2014, in final form 6 November 2014)

\begin{abstract}
The Argo dataset is used to study the winter upper-ocean conditions in the northeastern subtropical (NEA) Atlantic during 2006-12. During late winter 2010, the mixed layer depth is abnormally shallow and a negative anomaly of density-compensated salinity, the so-called spiciness, is generated in the permanent pycnocline. This is primarily explained by unusual weak air-sea buoyancy flux during the late winter 2010, in contrast with the five other studied winters. Particularly deep mixed layers and strong spiciness anomalies are observed during late winter 2012. The 2010 winter conditions appear to be related to historically low North Atlantic Oscillation (NAO) and high tropical North Atlantic index (TNA). Interannual variability of the eastern subtropical mixed layer is further investigated using a simple 1D bulk model of mean temperature and salinity linear profiles, based on turbulent kinetic energy conservation in the upper-ocean layer, and forced only with seasonal air-sea buoyancy forcing corresponding to fall-winter 2006-12. It suggests that year-to-year variability of the winter convective mixing driven by atmospheric buoyancy flux is able to generate interannual variability of both late winter mixed layer depth and spiciness in a strongly compensated layer at the base of the mixed layer and in the permanent pycnocline.
\end{abstract}

\section{Introduction}

At interannual to decadal frequencies, the variability of temperature signals in the interior pycnocline depends on whether they are associated or not with a density anomaly (Liu and Shin 1999; Schneider et al. 1999; Doney et al. 2007). The fraction of temperature anomalies associated with a density signature is governed by planetary wave dynamics. Temperature anomalies that are density compensated by salinity anomalies are referred to as spiciness anomalies. To a first order, they have no dynamical signature and are thus advected by the mean current like a passive tracer (e.g., Schneider et al. 1999; Lazar et al. 2001; Yeager and Large 2004; Luo et al. 2005; Tailleux et al. 2005; Nonaka and Sasaki 2007; Kolodziejczyk and Gaillard 2012). In the small range of temperature and salinity observed over the subtropical upper ocean, spiciness

Corresponding author address: Dr. Nicolas Kolodziejczyk, LOCEAN Laboratory, Sorbonne Universités (UPMC, University of Paris 6)-CNRS-IRD-MNHN, 4 Place Jussieu, F-75005, Paris, France.

E-mail: nicolas.kolodziejczyk@gmail.com anomalies are, to a first order, linearly proportional to the isopycnal temperature or salinity anomalies (e.g., Veronis 1972; Munk 1981; Jackett and McDougall 1985; Flament 2002). The advection of spiciness anomalies can potentially impact the interannual to decadal variability of tropical climate (Gu and Philander 1997; Schneider 2000, 2004), since they connect the surface of the eastern subtropical region, where they are generated, to the tropical regions, via the thermocline bridge (Yeager and Large 2004; Luo et al. 2005; Sasaki et al. 2010; Ren and Riser 2010; Li et al. 2012; Kolodziejczyk and Gaillard 2012; Katsura et al. 2013). In the subtropical North Atlantic, they also propagate to higher latitudes through the poleward western boundary current (Laurian et al. 2006).

The eastern subtropics are regions of formation of Subtropical Mode Waters of type II (Hanawa and Talley 2001). The formation of these mode waters results from wintertime air-sea fluxes as well as oceanic heat transport and eddy activity in the formation area (Hautala and Roemmich 1998; Hanawa and Talley 2001). The subtropical northeastern Atlantic (NEA) is also the region of formation of the Madeira Mode Water within the potential density layer $\sigma_{\theta}=26.5-26.8 \mathrm{~kg} \mathrm{~m}^{-3}$ (Käse et al. 1985; Siedler et al. 1987). 
A historical simplification used in the ventilation studies is that the late winter mixed layer (ML) properties are subducted, sliding continuously and adiabatically from the ML toward the interior thermocline and are not reentrained in the ML the following winter. The ventilated water mass properties reflect thus the late winter surface mixed layer conditions (e.g., Iselin 1939; Stommel 1979; Luyten et al. 1983; Woods 1985). This approximation has been efficiently used in ventilation studies to estimate mass and property exchange rates between the ML and the ocean interior (e.g., Nurser and Marshall 1991; Marshall et al. 1993; Qiu and Huang 1995; Lazar et al. 2002; Maze and Marshall. 2011; Liu and Huang 2012; Qu et al. 2013). In eastern regions of the ocean subtropical gyres, this framework has also been used to identify and quantify the interannual variability and subduction of density-compensated temperature-salinity anomalies (e.g., Nonaka and Sasaki 2007; Laurian et al. 2009), the so-called spiciness anomalies.

More recently, Yeager and Large $(2004,2007)$ have shown that spice injection below the deepest mixed layer in the eastern subtropical regions results from turbulent diapycnal mixing flux across the base of the ML. This process results from convective penetrative mixing at the ML base, analog to what occurs at the top of the atmospheric ML under unstable atmospheric conditions (e.g., Ball 1960; Izumi 1964; Turner 1973; Caughey 1982). In the ocean, it is primarily because of buoyancy loss and/or mechanical mixing and destabilizing salinity profile in the near-surface layer. The late winter convection produces a strongly density-compensated (SDC) layer at the base of the ML (de Boyer Montégut et al. 2004; Yeager and Large 2007), where salinity and temperature vertical gradients are enhanced, but strongly compensating each other, that is, the resulting vertical density gradient is reduced. In the southeastern subtropical Pacific region, Kolodziejczyk and Gaillard (2013) showed that the seasonal and interannual ML salinity budget is mainly balanced by the unresolved terms interpreted as turbulent vertical mixing terms because of convective entrainment, hence a $1 \mathrm{D}$ vertical process. During austral winter, the ML salinity loss is associated with an equal salinity gain in the interior pycnocline and with the formation of the SDC layer. This last study suggested that the spice injection could be intimately linked to the convective entrainment at the base of the ML.

The subduction and injection frameworks are thus distinct: in the subduction theory, "no density jump is permitted at the base of the mixed layer," hence "there is no turbulent entrainment flux at the base of the ML and the interior pycnocline is adiabatic" (Nurser and Marshall 1991, p. 1795; Marshall et al. 1993). Moreover, this theory does not consider the combined effects of both temperature and salinity profiles on density. In the subtropical regions, Yeager and Large $(2004,2007)$ provide evidence for the injection process, including turbulent entrainment flux associated with the discontinuity of the thermohaline profiles at the base of the ML.

The historical observations in the interior pycnocline at subtropical latitudes have established a vertical density ratio, quantifying the degree of compensation of the vertical gradients of temperature and salinity (Ruddick 1983), close to $R=2$ (Stommel 1993; Schmitt 1999; Ferrari and Rudnick 2000; Rudnick and Martin 2002). In contrast, in the surface layer of the eastern subtropics, the horizontal density ratio associated with the temperature and salinity horizontal gradients is reported to be rather close to $R=1$ for all horizontal scales in the injection region during late winter (Rudnick and Ferrari 1999; Johnson et al. 2012; Kolodziejczyk et al. 2014, manuscript submitted to J. Geophys. Res.). The formation of the SDC layer will reduce the density ratio of the interior pycnocline to values between $R=1$ and $R=2$ (Yeager and Large 2007; Kolodziejczyk and Gaillard 2013). In the NEA, Laurian et al. (2009) have numerically studied the linear relation between the surface properties and the subsurface spiciness anomalies, but have not investigated the spice injection mechanism.

Despite the studies by Yeager and Large (2007) and Kolodziejczyk and Gaillard (2013), it remains unclear how interannual variability of spice injection is linked to the interannual atmospheric and oceanic forcing. To answer these questions, the seasonal and interannual variability of ML depth and thermohaline properties are investigated in the subtropical NEA using a simple 1D vertical model derived from Niiler and Kraus (1977) ML turbulent kinetic energy (TKE) closure scheme. Among the turbulent ML model, it has been used extensively and successfully in the literature in order to derive models to simulate and rationalize the 1D ML balance at diurnal to seasonal time scales (e.g., Niiler and Kraus 1977; Price et al. 1986; Weller et al. 2004). In the NEA, previous observations and model studies have shown a dominant 1D dynamical balance between local air-sea flux and vertical mixing (Weller et al. 2004). To clarify the role of the interannual variability of winter on the air-sea flux, an identical mean idealized thermohaline profile has been chosen to initialize the vertical model, but interannual fall-winter mixing has been applied. Although this $1 \mathrm{D}$ vertical model does not explicitly represent the penetrative mixing process at the base of the ML, it allows the time evolution of thermohaline contrasts across the base of the mixed layer because of the vertical mixing and entrainment processes as parameterized in the TKE equation. Thus, in contrast with the Nurser and Marshall (1991) subduction framework, the assumption of "no entrainment" flux at the base of the ML is relaxed. In 

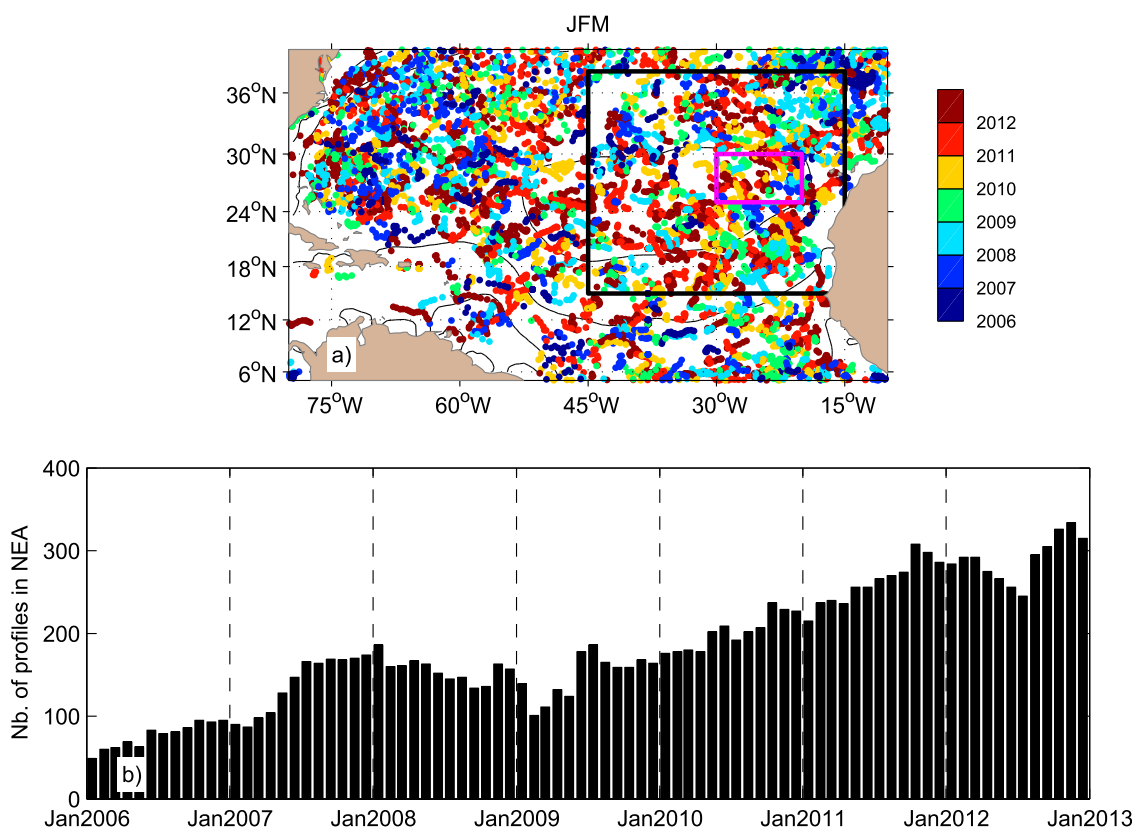

FIG. 1. (a) Spatial distribution of Argo profiles available during JFM between 2006 and 2012. The black square indicates the NEA box. The magenta box corresponds to $25^{\circ}-30^{\circ} \mathrm{N}$, $30^{\circ}-20^{\circ} \mathrm{W}$. (b) Temporal evolution of the number of Argo profiles available in the NEA box between 2006 and 2012.

the NEA subtropics, the period covering the winter 2006 to 2012 is well sampled with Argo profiles (Fig. 1) and displays events corresponding to well-defined atmospheric conditions, as, for example, the exceptionally negative phase of North Atlantic Oscillation (NAO) during winter 2009/10 (Buchan et al. 2014). It thus provides a panel of atmospheric and ocean conditions for case study purposes.

The paper is organized as follows: Section 2 presents the data and analysis method. Section 3 presents the 1D vertical model. The new results are presented in section 4 and summed up and discussed in section 5 .

\section{Data and method}

\section{a. Temperature and salinity profiles}

In this study, individual Argo profiles are used in the northern tropical and subtropical Atlantic between 2006 and 2012 (Fig. 1). They are downloaded from the Coriolis data center and then a climatological test was applied to the dataset, followed by a visual control and elimination of suspicious profiles.

Monthly gridded fields of temperature and salinity obtained from the In Situ Analysis System (ISAS) analysis are also used. ISAS is an optimal interpolation tool designed for the synthesis of the Argo global dataset (Gaillard et al. 2009). The optimal interpolation is computed over a $1 / 2^{\circ}$ grid and involves a structure function modeled as the sum of two Gaussian functions, each associated with specific time and space scales, resulting in a smoothing over typically $3^{\circ}$. The version used in this study is the V6 version named D7CA2S0 (http://archimer. ifremer.fr/doc/00115/22583/20271.pdf), which covers 2004 12. The gridded fields were produced over the global ocean $70^{\circ} \mathrm{N} / \mathrm{S}$ on a $1 / 2^{\circ} \times 1 / 2^{\circ}$ grid by the ISAS project with datasets downloaded from the Coriolis data center. The temperature and salinity fields are reconstructed on 152 levels ranging from 0 - to $2000-\mathrm{m}$ depth, with 5 -m vertical resolution in the top hundred meters then $10 \mathrm{~m}$ down to $800-\mathrm{m}$ depth. The major contribution is the Argo array of profiling floats, ranging from nearly 1500 profiles per month in 2004 to more than 9000 profiles per month in 2012. This data subset is complemented with the TAOPIRATA-Research Moored Array for African-AsianAustralian Monsoon Analysis and Prediction (RAMA) array of moorings in the tropical band. A few CTDs transmitted in real time are used, but XBTs and expendable CTDs (XCTDs) were excluded from the analysis because of uncertainties in the fall rate.

\section{b. Atmospheric reanalysis}

The 1D model has been forced with buoyancy fluxes constructed from the net surface heat flux and the atmospheric freshwater flux (evaporation minus precipitation) products. The first set of flux in use come from the 
ERA-Interim reanalysis (hereinafter ERA-I) provided by the European Center for Medium-Range Weather Forecasts (ECMWF) dataset (www.ecmwf.int/en/research/ climate-reanalysis/era-interim). We use monthly averaged $0.75^{\circ} \times 0.75^{\circ}$ gridded fields available for the $2006-12$ period.

The second set of fluxes is derived from the NCEPNCAR Reanalysis-1 project, which uses a state-of-the-art analysis/forecast system to perform data assimilation using past data from 1948 to present. Monthly gridded latent (LHF) and sensible (SHF) heat flux, shortwave (SWR) and longwave (LWR) radiation, evaporation $(E)$, and precipitation $(P)$ available for the period 2006-12 with a resolution of $1.5^{\circ} \times 1.5^{\circ}$ were downloaded (available online at www.esrl.noaa.gov/psd/data/gridded/data. ncep.reanalysis.html).

The third dataset of atmospheric fluxes is OAFlux. It consists of latent and sensible heat fluxes from objectively analyzed air-sea heat fluxes (Yu et al. 2008). This dataset is available on a $1^{\circ} \times 1^{\circ}$ grid for the time period 19562012. For the purpose of this study, we used the monthlymean fields during the period 2004-12. The $2.5^{\circ} \times 2.5^{\circ}$ gridded radiation products from the International Satellite Cloud Climatology Project (ISCCP) datasets (19832009) are provided by Dr. W. B. Rossow and distributed along with the OAFlux products (Zhang et al. 2004). We used monthly-mean radiative fluxes during the period 2004-09, and the missing radiative fluxes over 2010-12 are replaced by their mean seasonal cycle over 2004-09. As OAFlux does not provide a precipitation flux, the freshwater flux dataset is a combination of evaporation from the Yu et al. (2008) products (OAFlux) and precipitation from the Microwave Imager and Precipitation Radar onboard the Tropical Rainfall Measuring Mission satellite (TRMM; www.ssmi.com). Hereinafter, this dataset is referred to as OAFLUX-TMI.

Finally, the fourth dataset originates from ERA-I using the bias and amplitude corrections provided by an intercomparison between TAO-PIRATA-RAMA tropical moored measurements and ERA-I heat flux products (except for the shortwave radiation that is provided by ISCCP dataset) as done for TropFlux products (Praveen Kumar et al. 2012). As done for OAFLUX-TMI, the radiative fluxes over the period 2010-12 are replaced by their mean seasonal cycle over 2004-09. These fluxes are thus an extrapolation of TropFlux toward the subtropics $\left(40^{\circ} \mathrm{N} / \mathrm{S}\right)$, since the later fields originally only cover the $30^{\circ} \mathrm{N} / \mathrm{S}$ latitudinal band. The freshwater flux are from ERA-I. Hereinafter, this dataset will be referred to as TROPFLUX-EXT.

\section{c. Vertical and horizontal density ratio}

The buoyancy change due to the temperature and salinity is expressed as follows:

$$
g \frac{\Delta \rho}{\rho_{0}}=g \alpha \Delta \theta-g \beta \Delta S
$$

where $\Delta \rho, \Delta \theta$, and $\Delta S$ are any fluctuation of potential density, potential temperature, and salinity, respectively. The quantity $\rho_{0}=1025.5 \mathrm{~kg} \mathrm{~m}^{-3}$ is an ocean reference density, $g$ is the gravitational acceleration, and $\alpha$ and $\beta$ are the expansion coefficient of temperature and contraction coefficient of salinity, respectively. In this study, the degree of density compensation of vertical $\theta$ and $S$ gradients is quantified by the vertical density ratio $R$ or the vertical Turner angle $\mathrm{Tu}_{v}$ (Ruddick 1983; Yeager and Large 2007):

$$
\begin{aligned}
R_{v} & =\frac{\alpha \partial_{z} \theta}{\beta \partial_{z} S}, \text { and } \\
\mathrm{Tu}_{v} & =\operatorname{atan}\left(\frac{\alpha \partial_{z} \theta+\beta \partial_{z} S}{\alpha \partial_{z} \theta-\beta \partial_{z} S}\right) .
\end{aligned}
$$

Under conditions of a stabilized water column (i.e., $\partial_{z} \theta>0$ and $\left.\partial_{z} S<0\right), \mathrm{Tu}_{v}$ is within $\pm 45^{\circ}$; when a destabilizing salinity gradient is concomitant with a stabilizing temperature gradient, $\mathrm{Tu}_{v}>45^{\circ}$. If $\mathrm{Tu}_{v}>71.6^{\circ}\left(R_{v}<2\right)$, the process of double diffusion starts to be active (Turner 1973; Johnson 2006). When $\mathrm{Tu}_{v}$ gets close to $90^{\circ}\left(R_{v} \rightarrow 1\right)$, the buoyancy effects of $\partial_{z} \theta>0$ and $\partial_{z} S>0$ are of opposite signs, thus close to full density compensation (see Yeager and Large 2007; Johnson 2006).

The ISAS interpolated products from Argo data provide basin-scale, mapped, near-surface salinity and temperature. To compute the horizontal surface density ratio without choosing any arbitrary direction for the horizontal gradient, we have defined the complex horizontal density ratio $R_{H}$ for each month, following Ferrari and Paparella (2003):

$$
R_{H}=\frac{\alpha\left(\theta_{x}+\mathrm{i} \theta_{y}\right)}{\beta\left(S_{x}+\mathrm{i} S_{y}\right)} .
$$

The phase $\Phi$ of the complex horizontal density ratio $R_{H}$ quantifies the degree of alignment of $\theta$ and $S$ gradients. If the phase is $\Phi=0^{\circ}$ or $\Phi=180^{\circ}$, then there is thermohaline alignment. The magnitude of $R_{H}$ quantifies the relative strength of the gradients of $\theta$ and $S$. If $\left|R_{H}\right|=1$ and $\Phi=0^{\circ}$, then temperature and salinity cancel each other in the buoyancy balance and thermohaline compensation is achieved. A density ratio $\left|R_{H}\right|>1$ indicates that the temperature gradient has a dominant effect on the density gradient, while a density ratio of $\left|R_{H}\right|<1$ corresponds to a dominant effect of the salt gradient. 


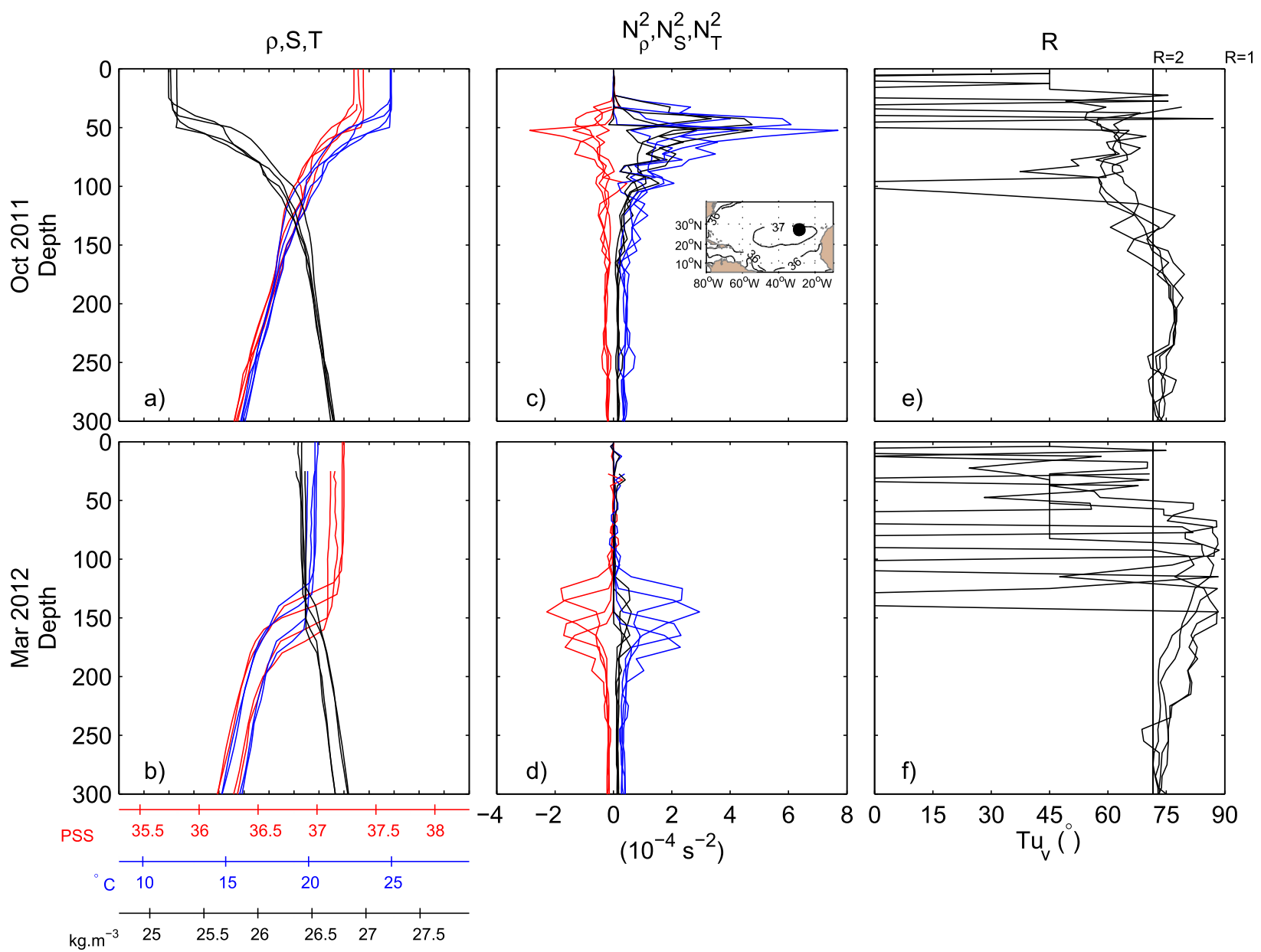

FIG. 2. (a),(b) Density (black; $\mathrm{kg} \mathrm{m}^{-3}$ ), temperature (blue; $\left.{ }^{\circ} \mathrm{C}\right)$, and salinity (red; pss) profiles; (c),(d) Brunt-Väisälä frequency (black; $\mathrm{s}^{-2}$ ), temperature (blue), and salinity (red) contribution to the Brunt-Väisälä frequency $\left(\mathrm{s}^{-2}\right)$; and (e), (f) vertical Turner angle $\left({ }^{\circ}\right)$. The profiles are taken around $27^{\circ} \mathrm{N}, 29^{\circ} \mathrm{W}$ [inset of (c)] in the NEA region during (top) October 2011 and during (bottom) March 2012.

\section{1D mixed layer model}

\section{a. Vertical thermohaline profiles}

During early fall 2011 (October) in the NEA (around $26^{\circ}-28^{\circ} \mathrm{N}, 29^{\circ}-28^{\circ} \mathrm{W}$; Fig. $2 \mathrm{a}$ ), the surface homogeneous layer, that is, the ML, is $50-60 \mathrm{~m}$ thick. At the base of the ML, the stratification increases abruptly up to $N^{2}=2-4 \times$ $10^{-4} \mathrm{~s}^{-2}$ (where $N$ is the Brünt-Väisälä frequency), then decreases to a near-constant value of $\sim 2-4 \times$ $10^{-5} \mathrm{~s}^{-2}$ below $\sim 100$-m depth (Fig. $2 \mathrm{c}$ ). The temperature and salinity profiles have a similar shape, but with an opposite sign to the density profiles (Figs. 2a,b), implying a destabilizing salinity effect compensating partially the temperature stabilizing contribution (Fig. 2c). Below the mixed layer, this results in a density ratio around $R=2$ (Fig. 2e).

During winter, the cooling due to air-sea fluxes induces a buoyancy loss from the surface layer. It destabilizes statically the water column (e.g., Turner 1973;
Marshall and Schott 1999) and triggers vertical convection (Yeager and Large 2007; Kolodziejczyk and Gaillard 2013). This produces vertical mixing of thermohaline properties between the mixed layer and permanent pycnocline, hence downward entrainment of the ML base. In March, it results in a ML deeper than $150-\mathrm{m}$ depth, and a step in thermohaline properties at the base of the ML (Figs. 2b,d). Between October and March, the vertical density ratio at the level of the density step has diminished to values below $R=2$ (Figs. 2e,f), indicating the formation of the SDC layer at the ML base (Yeager and Large 2007; Kolodziejczyk and Gaillard 2013).

In this section, we describe a simple 1D ML model derived from Niiler and Kraus (1977) and applied it to mean idealistic density (buoyancy), temperature, and salinity profiles (Fig. 3). The initial and final thermohaline profiles are depicted in Fig. 3 (dashed profiles). Each profile of thermohaline properties is defined as 


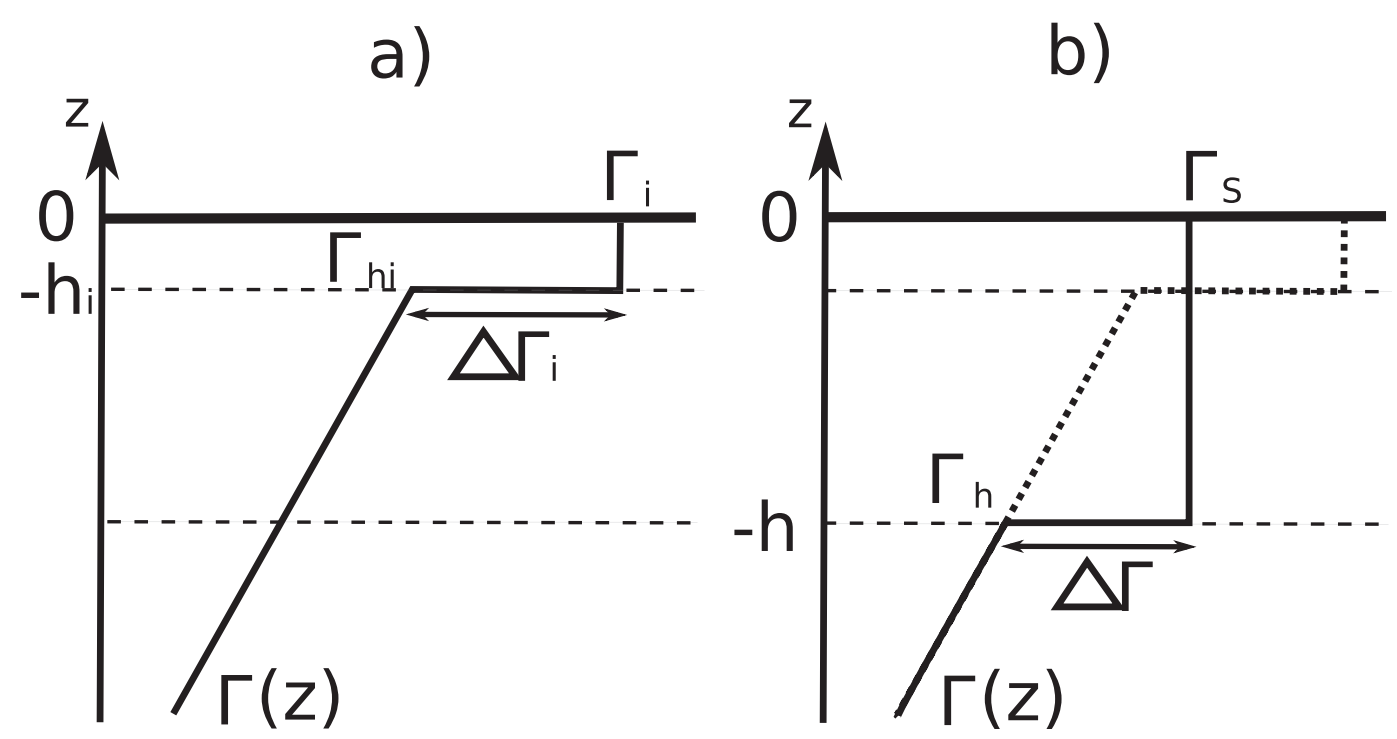

FIG. 3. (a) Idealized initial thermohaline profile in the NEA region (see Fig. 1a): $\Gamma_{\mathrm{i}}=\left\{b_{i}, S_{i}, T_{i}\right\}$ are the thermohaline initial values at the surface (see text), and $\Gamma_{h_{i}}=\left\{b_{h_{i}}, S_{h_{i}}, T_{h_{i}}\right\}$ are the thermohaline values at the base of the mixed layer at the initial depth $-h_{\mathrm{i}}$. (b) Idealized final thermohaline profile in the NEA region (see Fig. 1b): $\Gamma_{S}=$ $\left\{b_{S}, S_{S}, T_{S}\right\}$ are the final surface thermohaline values, and $\Gamma_{h}=\left\{b_{h}, S_{h}, T_{h}\right\}$ are the thermohaline values at the base of the mixed layer at the final depth $-h$.

$$
\begin{aligned}
& \Gamma(z)=N_{\Gamma}^{2}\left(z-h_{i}\right)+\Gamma_{h_{i}} ; \quad z<-h_{i}, \quad \text { and } \\
& \Gamma(z)=\Gamma_{i} ; \quad z>-h_{i},
\end{aligned}
$$

where $\Gamma=\{b, S, T\}$ is a seawater state variable (either buoyancy, salinity, or potential temperature, respectively). The term $-h_{i}$ is the initial depth of the ML (Fig. 3a), and $N_{\Gamma}=$ const is the linear vertical distribution of the buoyancy, salinity, or potential temperature below $-h$. The terms $\Gamma_{i}$ and $\Gamma_{h_{i}}$ are the values of the variable $\Gamma$ in the ML (and at the surface) and at the base of the ML, respectively. To focus on interannual variability of ML depth and thermohaline properties at its base due to the atmospheric forcing, the same initial profile is taken for each of the 200612 winters. For a given final depth $-h$, the conservation of integrated mass, temperature, and salinity must be satisfied between the initial (Fig. 3a) and final profiles (solid profile in Fig. 3b; for a complete derivation see the appendix).

\section{b. TKE equation}

The $1 \mathrm{D}$ vertical model of ML is dominated by turbulence that controls the entrainment velocity of the ML base, hence the ML depth [for more details see Niiler and Kraus (1977)]. Following Niiler and Kraus [1977, their Eq. (10.30)], the closure scheme of TKE can be written as

$$
\begin{aligned}
w_{e}\left(c_{i}^{2}-s v^{2}\right)= & 2 m u^{* 3}+\frac{h}{2}\left[(1+n) B_{0}\right. \\
& \left.-(1-n)\left|B_{0}\right|\right]+\left(h-\frac{2}{\gamma}\right) J_{0},
\end{aligned}
$$

where $w_{e}$ is the entrainment velocity of the interface at the ML base; $\boldsymbol{v}$ is the vertically averaged horizontal mixed layer velocity; $u^{* 3}=\sqrt{\tau / \rho}$ is the friction velocity ( $\tau$ is the surface wind stress and $\rho$ is the density of seawater); $h$ is the ML depth; $B_{0}$ is the surface buoyancy flux; $1 / \gamma$ is the shortwave extinction depth; $J_{0}=\left(g \alpha / \rho c_{p}\right) I_{0}$ ( $I_{0}$ is the shortwave radiation); $c_{i}^{2}=h \Delta b\left[\Delta b=g\left(\rho_{-h}-\right.\right.$ $\left.\rho_{a}\right) / \rho_{0}$ is the difference between the buoyancy at the ML base and the ML average]; and $s, n$, and $m$ are empirical proportionality factors. The first lhs term of Eq. (5) is the work done per unit time needed to lift the dense entrained water and to mix it through the layer; the second lhs term is the rate at which energy of the mean velocity field is reduced by mixing across the layer base. The first rhs term is the rate of work by the wind; the second rhs term is the rate of potential energy change produced by fluxes across the sea surface minus the ratio of potential energy dissipated in heat; and the third rhs term is the rate of potential energy change produced by penetrating solar radiation.

This study focuses on the season of winter cooling in the NEA. For that, Eq. (5) can be simplified by making the following hypothesis adapted to the region of subtropical NEA. During periods of cooling, there is a strong dependency on the depth $h$. The first and second lhs terms tend to increase with increasing depth. The other terms are either independent of $h$ or they decrease as the layer gets deeper. First, at the beginning of winter cooling the $\mathrm{ML}$ is around $50 \mathrm{~m}$ deep, and the penetration of both wind stress (that is weak in the eastern subtropical region) 
and solar radiation flux are negligible at the ML base (e.g., Morel and Antoine 1994; Sweeney et al. 2005). Thus, the first and last rhs terms in Eq. (5) can be neglected during boreal winter. Second, the vertical shear of the horizontal currents at the ML base is assumed to be weak in the northeastern subtropical Atlantic. Thus, the second lhs term in Eq. (5) can also be neglected. Third, another controlling factor is the relative magnitude of the wind stirring and thermal forcing, as expressed by the ratio

$$
\frac{2 u^{* 3}}{B_{0} h} \equiv \frac{L}{h},
$$

where $L$ can be interpreted as a generalized MoninObukhov length. When $L / h$ is large, the turbulence is due to wind stirring; convection due to buoyancy loss becomes the dominant factor when the ratio is small. During fall and winter in the NEA, typical values are $u^{*} \sim 0.01 \mathrm{~m} \mathrm{~s}^{-1}$, $B_{0} \sim 10^{-7} \mathrm{~m}^{2} \mathrm{~s}^{-3}$, and $h \sim 100-\mathrm{m}$ depth gives $L / h \sim 0.1$ (Niiler and Kraus 1977). During boreal winter, the flux of buoyancy from the ocean toward the atmosphere is counted positive, $B_{0}>0$. Finally, in the NEA, Eq. (5) can be reduced to

$$
\frac{d h}{d t}=\frac{n B_{0}}{\Delta b},
$$

where $d h / d t=w_{e}>0$ is the entrainment velocity at the base of the ML, and $n$ is the mixing efficiency factor, that is, the fraction of kinetic energy that is effectively used to remove potential energy. It is therefore worth noticing that if $n=0$, no density discontinuity can be maintained at the base of ML (see the appendix for further discussion). Equation (7) describes the deepening of ML due to winter buoyancy loss alone. Such 1D dynamics have been suggested for subtropical eastern regions by Yeager and Large (2007) and Kolodziejczyk and Gaillard (2013). To solve explicitly Eq. (7), the expression of the density step at the ML base $\Delta b$ must be computed. This will be done in the case of idealistic profiles from Eq. (4) (Fig. 3) and with the equations of conservation of temperature, salinity, and buoyancy, which are extensively derived in the appendix.

\section{c. Density ratio}

In the subtropical thermocline, the density ratio is usually found to be close to $\mathrm{Tu}_{v}=71.6^{\circ}\left[R_{v} \sim 2\right.$; Eq. (2); Stommel 1979; Rudnick and Ferrari 1999; St. Laurent and Schmitt 1999; Schmitt 1999; Rudnick and Martin 2002; Yeager and Large 2007]. This is confirmed by Fig. 2e, showing the profiles of density ratio in the NEA region. Equations (2a) and (2b) are used to compute the
Turner angle and density ratio with the idealized profiles from the model. Below the base of the ML, the vertical density ratio and Turner angle are related to the stratification by

$$
\begin{aligned}
R_{N} & =\frac{N_{T}}{N_{S}}, \quad \text { and } \\
\mathrm{Tu}_{N} & =\operatorname{atan}\left(\frac{N_{T}+N_{S}}{N_{T}-N_{S}}\right) .
\end{aligned}
$$

On the other hand, the expression of the vertical density ratio $R_{v}$ of the thermohaline step at the ML base can be written

$$
\begin{aligned}
R_{v} & =\frac{\alpha \Delta T}{\beta \Delta S}, \text { and } \\
\mathrm{Tu}_{v} & =\operatorname{atan}\left(\frac{\alpha \Delta T+\beta \Delta S}{\alpha \Delta T-\beta \Delta S}\right) .
\end{aligned}
$$

where $\Delta T$ and $\Delta S$ are the thermohaline steps given by Eqs. (A4a) and (A4b) in the appendix. At the ML base, convective mixing is likely to inject spiciness in a boundary layer characterized by a density-, temperature-, and salinity-enhanced gradient (Yeager and Large 2007). During late winter, in subtropical regions, Yeager and Large (2007) found values of the vertical Turner angle $\mathrm{Tu}_{v}$ larger than $75^{\circ}$ at the ML base. In the 1D model, the enhanced gradient is modeled as a thermohaline step that is associated with the convective entrainment at the base of the ML. Of course, in the real ocean, such an abrupt vertical thermocline step cannot exist, but corresponds to the steeper vertical gradient of density, temperature, and salinity at the ML base, as shown in Fig. 2.

\section{Results}

\section{a. Winter mean state and interannual variability}

In the subtropical-tropical Atlantic, the most noticeable feature is the surface salinity maximum (SSM) of 37.5 pss or more, centered around $24^{\circ} \mathrm{N}-40^{\circ} \mathrm{W}$ (Fig. 4a), while sea surface temperature (SST) monotonically increases southward from $15^{\circ}$ to $28^{\circ} \mathrm{C}$ (Fig. 4b). South of $24^{\circ} \mathrm{N}$ (center of the SSM), the horizontal temperature and salinity gradients are close to being aligned with an opposite sign (Fig. 4d), and hence they constructively enhance the horizontal density gradient in the tropics (Fig. 4e). Furthermore, in the western tropics, the salinity gradient mainly controls the density gradient because of the large front due to negative $\mathrm{E}-\mathrm{P}$ and AmazonOrinoco River runoff (Reverdin et al. 2007). In contrast, 
$\mathrm{MARCH}$
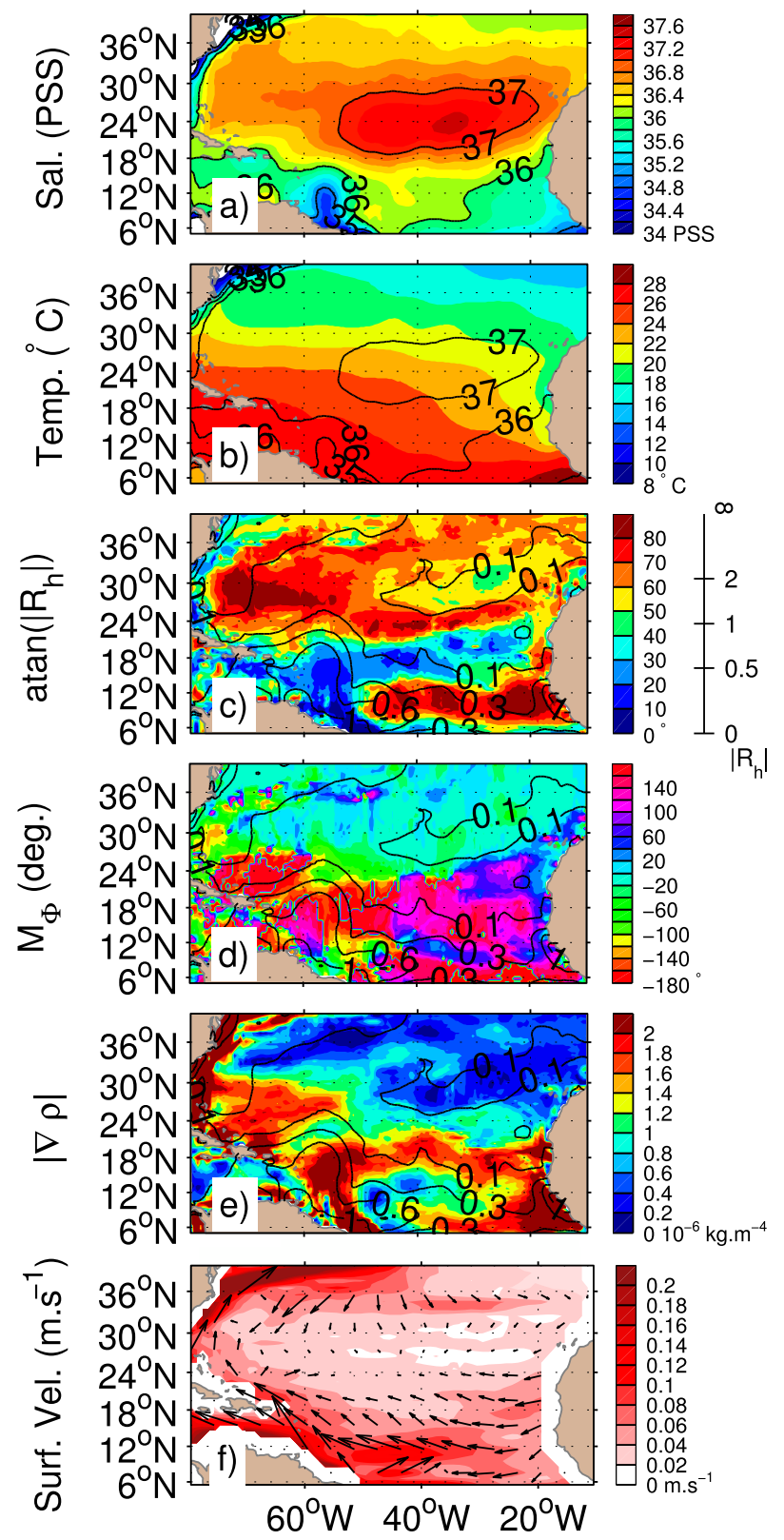

FIG. 4. Subtropical North Atlantic (a) mean SSS (pss), (b) mean SST $\left({ }^{\circ} \mathrm{C}\right),(\mathrm{c})$ median of the norm of the surface horizontal density ratio [atan $\left(\left|R_{h}\right|\right)$; shaded], (d) mean angle of the surface horizontal density ratio $\left({ }^{\circ} \mathrm{C}\right),(\mathrm{e})$ mean norm of the surface density gradient $\left(\mathrm{kg} \mathrm{m}^{-4}\right)$ in March from ISAS analysis between 2004 and 2012, and (f) mean March surface velocity $\left(\mathrm{m} \mathrm{s}^{-1}\right)$ and direction of the current computed from OSCAR (www.oscar.noaa.gov/) surface current analysis between 2004 and 2012. In (c),(d), and (e) the STD of SSS (pss) is also plotted (contours).

north of $24^{\circ} \mathrm{N}$, the horizontal temperature and salinity gradients are aligned with the same sign (Fig. 4d) and tend to compensate each other (Kolodziejczyk et al. 2014, manuscript submitted to J. Geophys. Res.). The

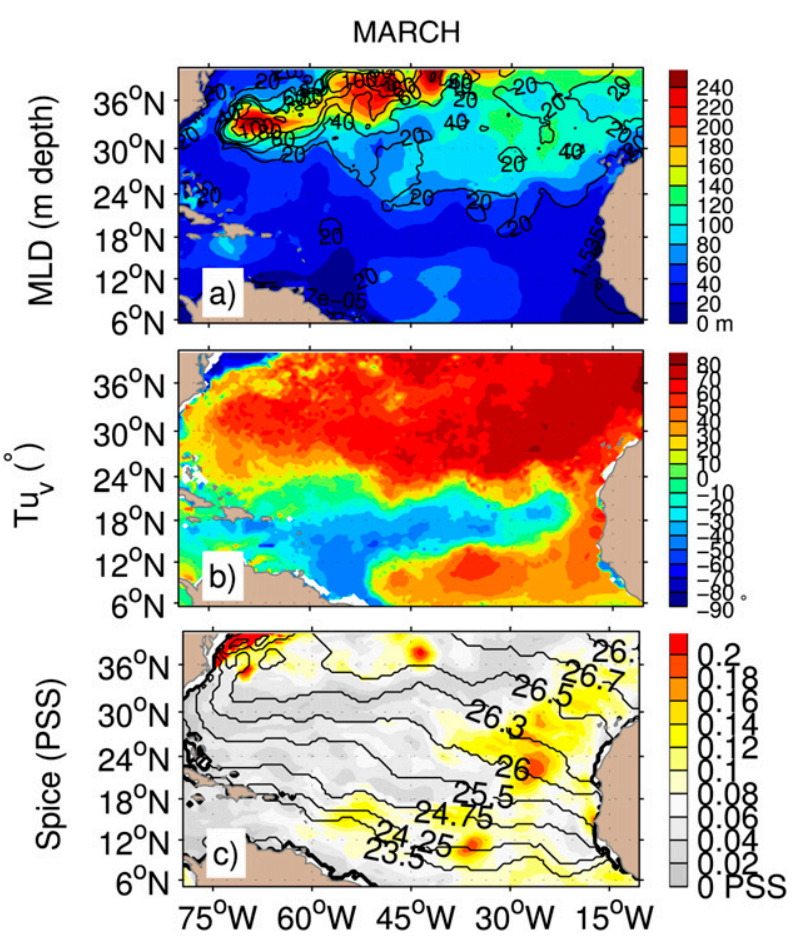

FIG. 5. March subtropical North Atlantic (a) mean mixed layer depth ( $\mathrm{m}$; color shading) and interannual STD of mixed layer depth (m; contours), (b) median vertical Turner angle $\left(^{\circ}\right)$ taken at the base of the mixed layer, and (c) interannual STD of the spiciness anomalies (pss; color shading) on the isopycnal layer closest to the maximum mixed layer depth and the corresponding most equatorward position of the isopycnals $\left(\mathrm{kg} \mathrm{m}^{-3}\right.$; contours) between 2004 and 2012 from ISAS analysis.

near-horizontal compensation is mostly achieved in the NEA region and the Gulf Stream region ( $R \sim 1$; Fig. $4 \mathrm{c})$. In contrast with the Gulf Stream region, the NEA region is a region of relatively small surface currents during March (Fig. 4f). It is worth noticing that it is associated with a low surface horizontal density contrast and sea surface salinity (SSS) interannual standard deviation (STD) larger than 0.1 pss (Fig. 4e; Kolodziejczyk et al. 2014, manuscript submitted to J. Geophys. Res.).

Interestingly, in March, ML depth presents comparable patterns to those of the distribution of horizontal density gradient (cf. Fig. 4e and Fig. 5a). South of $24^{\circ} \mathrm{N}$, ML depth remains shallow (around 50-m depth) in a region of sharp surface horizontal density gradient, while north of $24^{\circ} \mathrm{N}$, the deep MLs (between 100- and 250-m depth) are associated with the lower horizontal density gradient (Figs. 4e and 5a). In late winter north of $18^{\circ} \mathrm{N}$, the interannual STD of ML depth presents also the largest values greater than $20 \mathrm{~m}$ (Fig. 5a).

Just below, at the ML base, the late winter median vertical Turner angle computed from Eq. (2b) shows the highest values in the NEA $\left(\mathrm{Tu}_{v} \rightarrow 90^{\circ}\right.$ or $\left.R \rightarrow 1\right)$ (Fig. 5b). These high vertical Turner angle values are 
Buoyancy Flux (JFM)
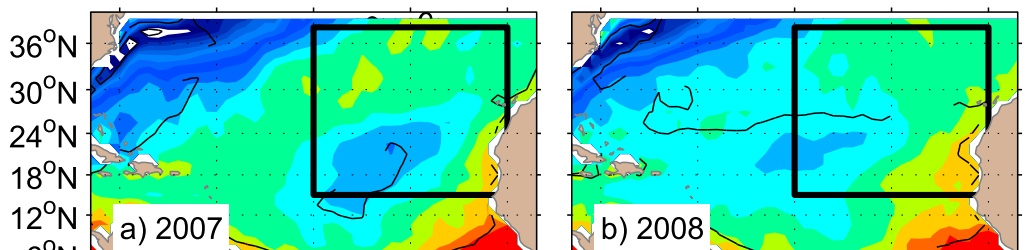

b) 2008
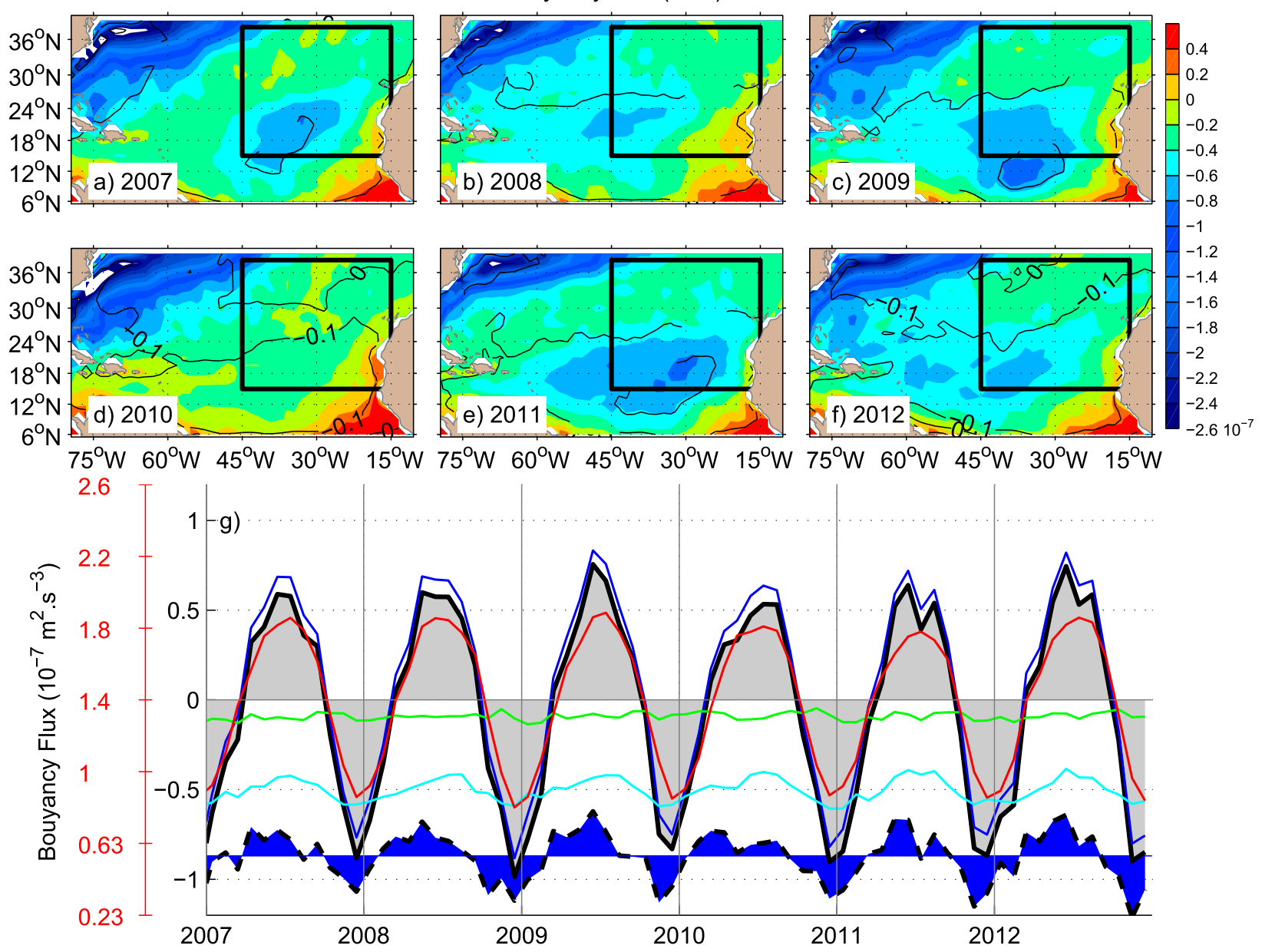

FIG. 6. (a)-(f) Subtropical North Atlantic distribution of mean buoyancy flux $\left(\mathrm{m}^{2} \mathrm{~s}^{-3}\right.$; shaded) and evaporation minus precipitation flux contribution to the buoyancy flux $\left(10^{-7} \mathrm{~m}^{2} \mathrm{~s}^{-3}\right.$; contours) during each winter (JFM) between 2007 and 2012. (g) Time series of buoyancy flux (thick black); heat flux (thin blue), E - P flux (thin green), latent heat flux (dashed thick black and blue), longwave plus sensible heat flux (thin cyan), and shortwave (thin red); note that the shortwave curve (thin red) is shifted in order to facilitate the comparison (red axis). The time series are taken within the $15^{\circ}-37^{\circ} \mathrm{N}, 45^{\circ}-15^{\circ} \mathrm{W}$ box in the NEA region. The fluxes are counted positively toward the ocean.

located in the highly compensated horizontal surface thermohaline gradients region materialized by the density ratio around $R \sim 1$ in Fig. 4c. In the NEA, this indicates the presence of the SDC layer and intense spice injection at the base of the mixed layer (de Boyer-Montégut et al. 2004; Yeager and Large 2007; Liu et al. 2009; Kolodziejczyk and Gaillard 2012). This is confirmed by the strongest spiciness anomaly interannual STD (0.16 pss) within the $\sigma_{\theta}=25.5-26.9$ isopycnal range at the base of the deepest ML during late winter (March; Fig. 5c). During boreal winter, both mixed layer depth and surface density distribution seasonal and interannual variability are related to change in buoyancy over the surface layer. Following Weller et al. (2004), in the NEA subtropics, the surface buoyancy loss during winter is mainly explained by the atmospheric winter cooling.

\section{b. Atmospheric fluxes}

During boreal winter [January-March (JFM)] in the tropics-subtropics, the buoyancy loss (computed from ERA-I) varies from about $0.2 \times 10^{-7} \mathrm{~m}^{2} \mathrm{~s}^{-3}$ in the NEA region to $2 \times 10^{-7} \mathrm{~m}^{2} \mathrm{~s}^{-3}$ in the Gulf Stream region (Figs. 6a-f). The buoyancy losses in the tropical-subtropical Atlantic present an important interannual variability, especially the weaker losses during 2010 (Figs. 6d,g).

In the NEA, the variability of atmospheric buoyancy flux presents a dominant annual cycle (Fig. 6g; black thick curve), which is mainly driven by the atmospheric heat flux (Fig. 6g; thin dark blue curve). Although the E - P flux contributes to a slight buoyancy loss due to evaporation excess (Fig. 6g; green curve), its variability is too weak to modulate the total buoyancy flux variability. During boreal winter, the buoyancy loss is strongly 

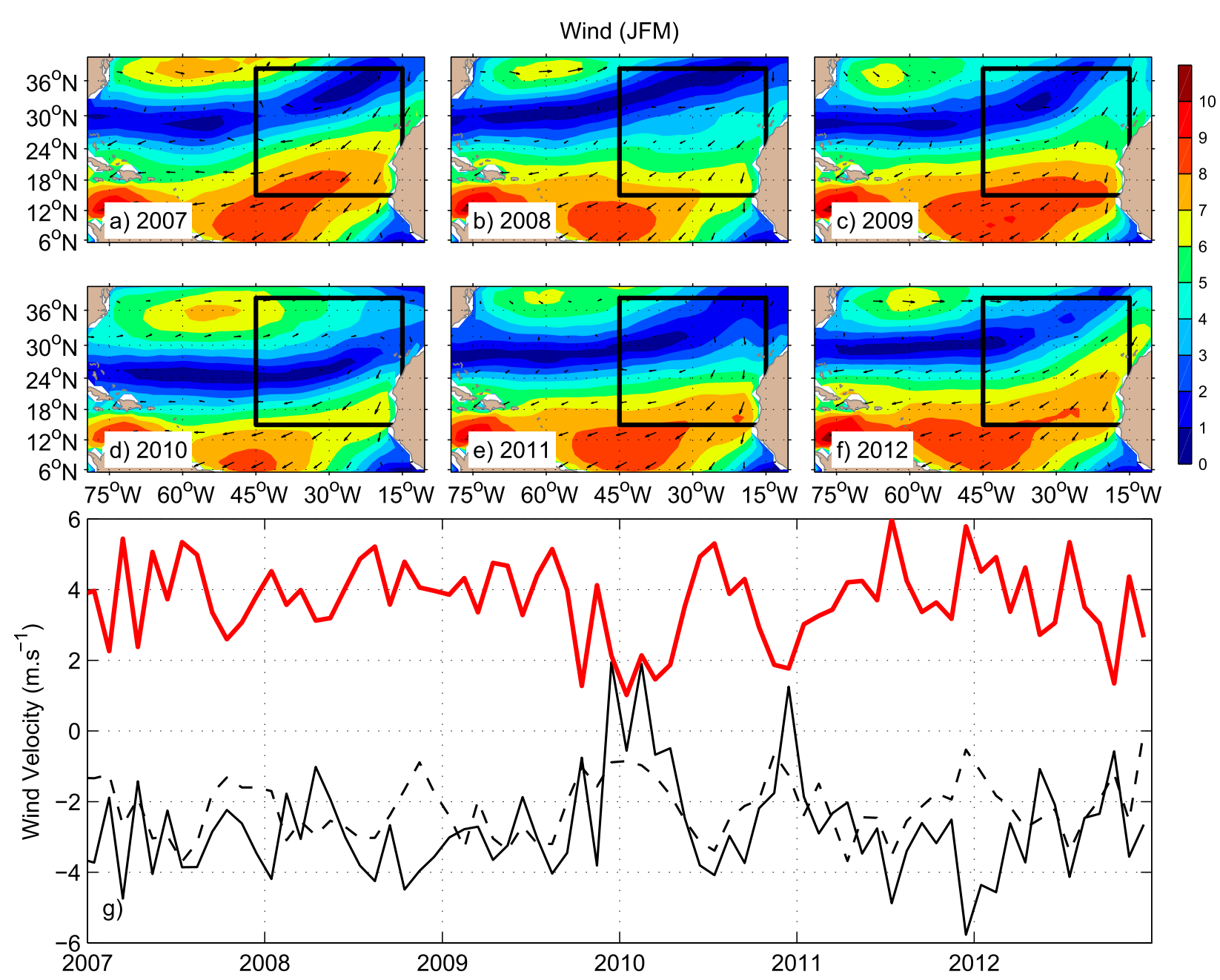

FIG. 7. (a)-(f) Subtropical North Atlantic distribution of mean wind velocity ( $\mathrm{m} \mathrm{s}^{-1}$; shaded) and direction (arrows) during each winter (JFM) between 2007 and 2012. (g) Time series of wind speed (thick red); zonal (thin solid black) and meridional (thin dashed black) wind components between 2007 and 2012.

modulated by latent heat loss and the combination of longwave radiation and sensible heat flux (Fig. 6; thick dashed black and cyan curves). In the NEA, during JFM 2010, latent heat loss is anomalously weaker than during the other winters (Figs. 6d,g; black dashed thick curve). This is explained by weaker trade winds during boreal winter 2010 in the northern NEA box (Figs. 7d,g) because of their anomalous southward shift. In contrast, during boreal winter 2012, they present strong positive anomalies. This situation is associated with a less intense and more southward position of the Azores high atmospheric pressure center during the winter 2010 (Figs. 7d,g).

\section{c. Sea surface thermohaline properties}

Between 2006 and 2012, over the tropical-subtropical North Atlantic, the main feature in the interannual variability of SST is the anomalous strong warming of the eastern and central tropical Atlantic during boreal winter 2010 (Figs. 8a,b; black curve).

In the eastern tropics, the major contributor to sea surface density (SSD) interannual variability (Fig. 8d) is SST (Fig. 8a), while in the western tropics, it is SSS (Fig. 8c). In the NEA subtropics, the interannual SST anomalies mainly contribute to the interannual SSD anomalies (SSDA; Figs. 8a,b). During boreal winter 2010 , the anomalously warm tropical SST south of $24^{\circ}-$ $30^{\circ} \mathrm{N}$, because of anomalous weak trade wind, explains the dramatic decrease of SSD in the southern NEA region that may increase vertical stratification and prevent ML deepening in the southern NEA box.

On the other hand, north of $24^{\circ}-30^{\circ} \mathrm{N}, \mathrm{SSD}$ experiences weaker interannual variability (Fig. 8d). This is explained by lower interannual variability of SST anomalies (SSTA) and SSS anomalies (SSSA) and counteracting effects 

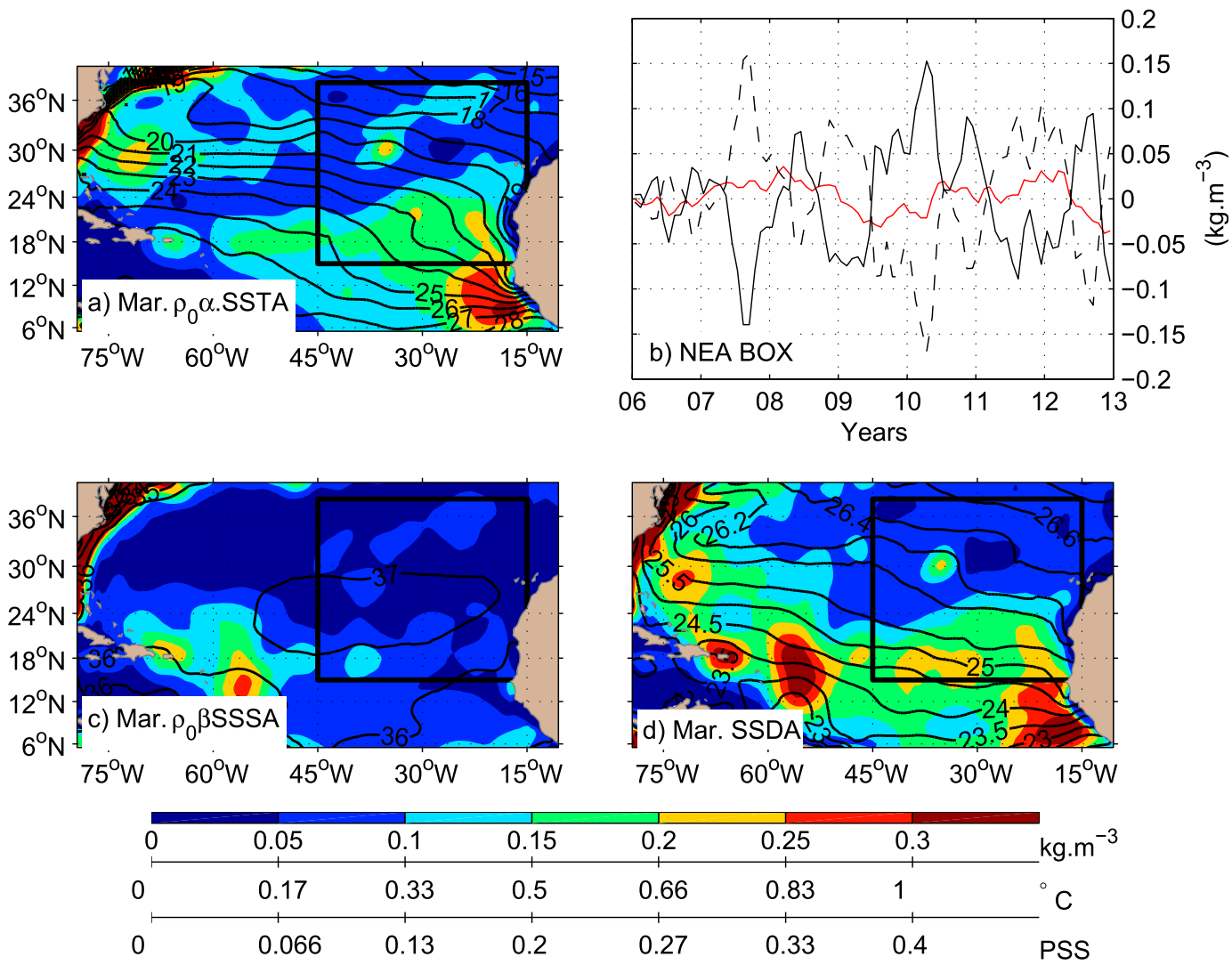

FIG. 8. (a) Interannual STD of SST anomalies (shaded) and mean SST $\left({ }^{\circ} \mathrm{C}\right.$; contours); (b) time series of the SST (solid black), SSS (solid red), and SSD (dashed black) anomalies taken within the $15^{\circ}-37^{\circ} \mathrm{N}, 45^{\circ}-15^{\circ} \mathrm{W}$ box in the NEA region. (c) Interannual STD of SSS anomalies (shaded) and mean SSS (pss; contours). (d) Interannual STD of SSD anomalies (shaded) and mean SSD ( $\mathrm{kg} \mathrm{m}^{-3}$; contours). The SST and SSS anomalies are normalized by $\rho_{0} \alpha$ and $\rho_{0} \beta$, respectively, in order to be homogeneous with the SSD anomalies, thus expressed in $\mathrm{kg} \mathrm{m}^{-3}$. The color bar is identical for the SSS, SST, and SSD interannual STD fields. The corresponding value in temperature and salinity is shown below the color bar.

between SSTA and SSSA that contribute to reduce SSDA (Figs. 8a,c,d).

\section{d. Mixed layer depth}

The interannual differences in winter buoyancy fluxes are likely to influence winter ML depth and thermohaline properties. The depth of the March ML are computed from the ISAS fields that are compared with the one derived from the integration of the 1D ML model from October to March (Fig. 9; color shading and black contours). In the NEA subtropics (east of $50^{\circ} \mathrm{W}$ ), during the late boreal winter 2009 and 2012 deep ML, larger than $120-\mathrm{m}$ depth is observed and modeled within $24^{\circ}-30^{\circ} \mathrm{N}$ (Figs. 9c,f; color shading). In contrast, during March 2010, a shallower ML (less than 100-m depth) is observed and modeled around $24^{\circ}-30^{\circ} \mathrm{N}$ (Fig. 9d). In spite of a slightly deeper ML in the model, the spatial structures of ML depth interannual variability are shown to be driven by the air-sea buoyancy flux and convective entrainment.
To test the sensitivity of the results to the atmospheric flux products, the ML depth has been computed with the ERA-I (reference product), NCEP, OAFLUX+TMI, and TROPFLUX-EXT products (Fig. 10a). In $25^{\circ}-30^{\circ} \mathrm{N}, 30^{\circ}-$ $20^{\circ} \mathrm{W}$ in the NEA region (see Fig. 9), the main differences between the atmospheric buoyancy fluxes computed with the various products originate mainly from the heat flux (not shown). The NCEP product exhibits the strongest heat loss during boreal winters between 2007 and 2012 (Fig. 10a). This is probably explained by the strong negative bias reported in the NECP reanalysis (about $-30 \mathrm{~W} \mathrm{~m}^{-2}$; Praveen Kumar et al. 2012). However, the interannual variability of the March ML depth shows a minimum in 2010, and the deepest ML in 2009 and 2012, which is qualitatively compatible with the observed one (Fig. 10b). In contrast, during the boreal winter, OAFLUX+TMI buoyancy fluxes are systematically weaker than the ones computed from ERA-I (Fig. 10a). The ML depth computed from the OAFLUX shows the 


\section{MIXED LAYER DEPTH}
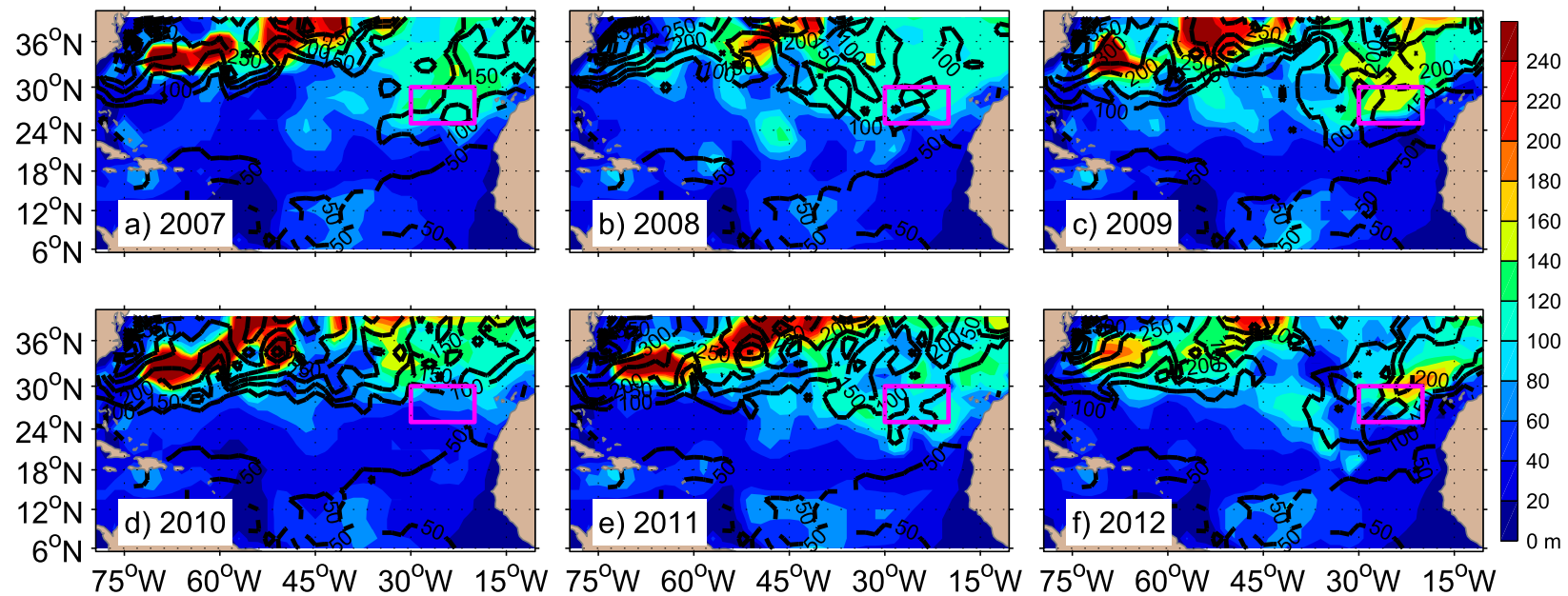

FIG. 9. Mixed layer depth (m) in March from ISAS analysis (color shading) between 2007 and 2012 and from 1D model (black contours) integrated from October to March each fall-winter between $2006 / 07$ and 2012 . The magenta box corresponds to $25^{\circ}-30^{\circ} \mathrm{N}, 30^{\circ}-20^{\circ} \mathrm{W}$.

smallest interannual variability (Fig. 10b). Eventually, the TropFlux and ERA-I-derived buoyancy flux give close results and a qualitatively similar interannual variability of ML depth (Fig. 10b).

\section{e. Vertical thermohaline properties}

To further investigate the vertical evolution of thermohaline profiles in the NEA during boreal winter and to enhance the year-to-year contrasts, the NovemberJanuary-March evolution of thermohaline profiles for winters 2009/10 (shallow ML case) and 2011/12 (deep ML case) have been plotted both from individual Argo profiles and from the model outputs (Fig. 11). The Argo profiles and model output have been taken, as above, within a box defined between $25^{\circ}$ and $30^{\circ} \mathrm{N}$ and $30^{\circ}$ and $20^{\circ} \mathrm{W}$ in the NEA region (see Fig. 9).

In the NEA box, these two years cover the range of buoyancy-driven ML deepening and SDC formation due to convection. During boreal winter 2009/10, the smaller buoyancy loss results in a shallower ML that does not exceed 150-m depth in late winter (February 2010; Figs. 11i,j), whereas ML can reach more than 200-m depth in March 2012 (Figs. 11k,1). The first-order control of the deepening of the mixed layer due to convective entrainment is confirmed by the $1 \mathrm{D}$ ML model (Figs. 11b,f,j and 11d,h,l). Although, other processes are neglected and the model is integrated from the common initial idealized stratification, it reproduces reasonably not only the time evolution of the thermohaline vertical profiles between November and March, but also its interannual variability.

A close examination of the observation and model results reveals a key feature due to the convective entrainment. At the modeled ML base, the step in thermohaline properties is intrinsically produced by the entrainment [Eq. (7)] (Kraus and Turner 1967; Niiler and Kraus 1977) and deepens along with the ML depth evolution (Figs. 11a,b). This thermohaline step corresponds to the SDC layer present in both observation and model (Figs. 11a-1); it characterizes the ML base in the penetrative convective mixing framework described in Yeager and Large (2007). Furthermore, during late winter, the SDC is associated with spice injection at the ML base since the temperature, salinity, and density of the pycnocline are increased by $\Delta T, \Delta S$, and $\Delta \rho$, respectively (Figs. 2, 11).

In the idealized model, the SDC layer is concentrated in the density step that has theoretically no thickness, but presents the properties of the SDC: (i) a high level of vertical compensation increasing until late winter with a Turner angle greater than $\mathrm{Tu}_{v}=75^{\circ}-80^{\circ}$ in March (Figs. 12a,b) and (ii) injection of thermohaline anomalies at the base of the mixed layer (Fig. 11). In the NEA, in spite of smaller values of the observed vertical Turner angle $\mathrm{Tu}_{v}$ at the base of the ML, that is, within the thermohaline step, its fall-to-winter increase is qualitatively reproduced by the model simulation (Figs. 12a,b). This confirms to a first order the primary role of convective entrainment in producing such a SDC layer associated with the mixed layer deepening due to winter buoyancy loss.

The March distribution of the vertical Turner angle at the mixed layer base, that is, within the SDC layer, exhibits comparable spatial structures between observation and model. In spite of a too high Turner angle value in the model, the interannual structure of the SDC layer is qualitatively reproduced with the model (Fig. 13). In March, the larger domain of SDC layers is achieved during the late winters 2009, 2011, and 2012 (Figs. 13c,e,f). 

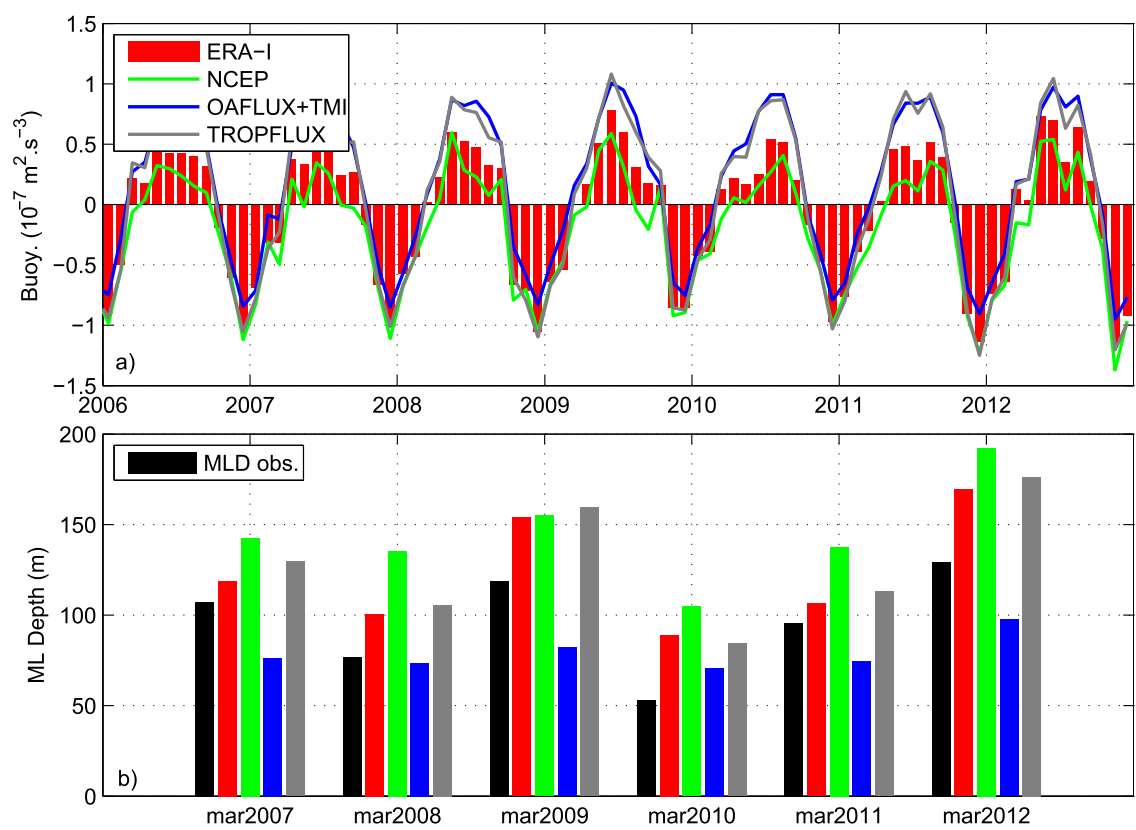

FIG. 10. (a) Buoyancy flux computed from ERA-I (red bars), NCEP (green curve), OAFLUXTMI (blue curve), and TROPFLUX-EXT (gray curve) within the $25^{\circ}-30^{\circ} \mathrm{N}, 30^{\circ}-20^{\circ} \mathrm{W}$ box. (b) March mixed layer depth observed (black bars) and computed from the 1D model forced by ERA-I (red bars), NCEP (green bars), OAFLUX-TMI (blue bars), and TROPFLUX-EXT (gray bars) within the $25^{\circ}-30^{\circ} \mathrm{N}, 30^{\circ}-20^{\circ} \mathrm{W}$ box for each year from 2007 to 2012 .

In contrast, during late winter 2010, both simulation and observation exhibit the lowest values of the vertical Turner angle, and the SDC layer does not extend as far southward as during late winters 2009, 2011, and 2012 (Fig. 13d). To a first order, this suggests that the atmospheric buoyancy flux spatial structure has a major effect on the SDC layer formation. As previously reported, the quantitative difference may be because of the accuracy of flux products, the double diffusion of thermohaline properties in the SDC layer not included in the 1D model (St. Laurent and Schmitt 1999), and advection in the permanent pycnocline (Weller et al. 2004).

\section{f. Spice injection}

The spiciness anomaly is computed on density surfaces located at the base of the deepest mixed layer in both observation and 1D model during late boreal winter (March) for each year between 2007 and 2012 (Figs. 14a-l and see also Fig. 5c). In the NEA, in spite of slightly more intense anomalies and some discrepancies in particular during winters 2008 and 2010, the observed interannual spiciness anomalies patterns (Figs. 14a-c and $14 \mathrm{~g}-\mathrm{i}$ ) are qualitatively reproduced by the $1 \mathrm{D}$ convective model (Figs. $14 \mathrm{~d}-\mathrm{f}$ and $14 \mathrm{j}-1$ ). During winters 2009 and 2012, the strongest positive spiciness anomalies (up to $0.35 \mathrm{pss}$ ) are observed spreading from about $24^{\circ} \mathrm{N}$, $40^{\circ} \mathrm{W}$ to $35^{\circ} \mathrm{N}, 15^{\circ} \mathrm{W}$ (Figs. $14 \mathrm{c}$, f and $14 \mathrm{i}, 1$ ). In contrast, during late winter 2010, negative spiciness anomalies (about -0.15 pss) are observed, but slightly overestimated in the 1D simulations (about $-0.25 \mathrm{pss}$ ) (Figs. 14g,j). Also, in NEA between $30^{\circ}$ and $45^{\circ} \mathrm{W}$, positives anomalies are noticeable that are not as intense in the data (Figs. 14g,j). Nevertheless, during late boreal winter 2008 in the NEA, the north-south dipole of spiciness around $30^{\circ} \mathrm{N}$ (Fig. 14b) is not as well reproduced with the model (Fig. 14e), a positive spiciness anomaly is observed around $30^{\circ} \mathrm{N}-30^{\circ} \mathrm{W}$ (Fig. 14e). During March 2011, the model also reproduces the negative spiciness anomaly found off the African coast in the eastern NEA (Figs. 14h,k). On the other hand, the 1D simple model based on the convective adjustment alone misses the possible contribution of the other vertical turbulent terms of Eq. (5), the horizontal advection of salt, and the contribution of unresolved mesoscale and submesoscale dynamics. The missing contributions may explain the discrepancies observed between the model and observations and are further discussed in the following section.

\section{Discussion and conclusions}

This study provides more insights into the injection mechanism of temperature and salinity anomalies that takes place at the base of the ML during late boreal 


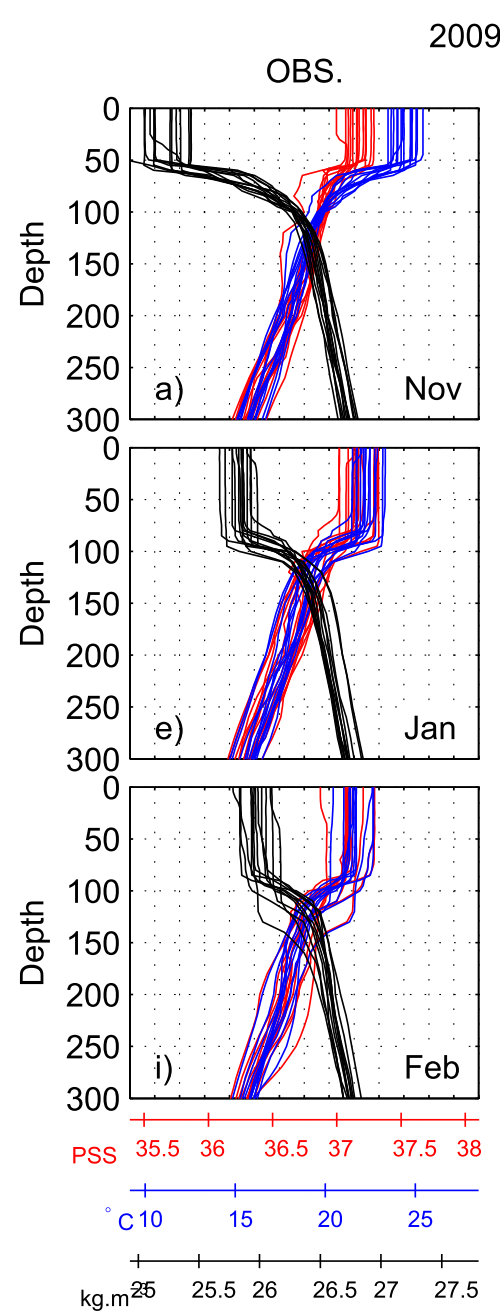

2009-10

MODEL
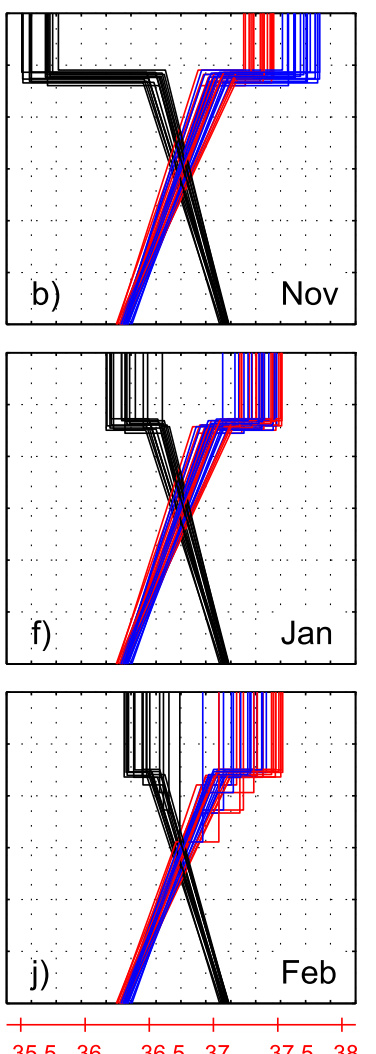

$\begin{array}{llllll}35.5 & 36 & 36.5 & 37 & 37.5 & 38\end{array}$

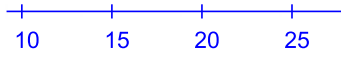

\begin{tabular}{llllll}
\hline 25 & 25.5 & 26 & 26.5 & 27 & 27.5
\end{tabular}

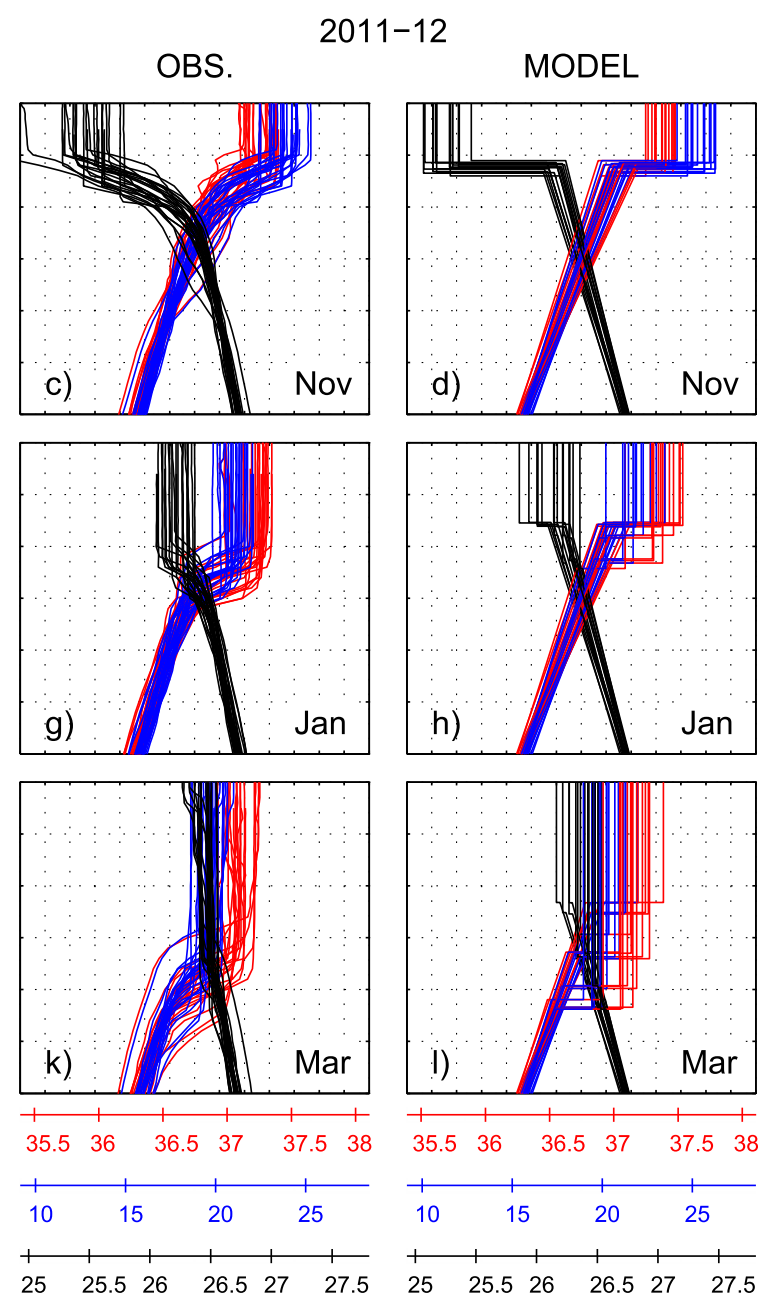

FIG. 11. Density (black; $\mathrm{kg} \mathrm{m}^{-3}$ ), temperature (blue; ${ }^{\circ} \mathrm{C}$ ), and salinity (red; pss) profiles from (a),(e),(i),(c),(g),(k) Argo and from the (b), (f), (j), (d), (h),(l) $1 \mathrm{D}$ model taken within $25^{\circ}-30^{\circ} \mathrm{N}, 30^{\circ}-20^{\circ} \mathrm{W}$ in the NEA region in (top) November, (middle) January, and (bottom) February and March during fall-winter (left) 2009-10 and (right) 2011-12.

winter (e.g., Yeager and Large 2004, 2007; Kolodziejczyk and Gaillard 2012, 2013) by relaxing the hypotheses of continuity of density at the base of the ML associated with the subduction (no entrainment flux) (e.g., Nurser and Marshall 1991; Marshall et al. 1993; Qiu and Huang 1995; Nonaka and Sasaki 2007; Laurian et al. 2009; Maze and Marshall 2011; Liu and Huang 2012; Qu et al. 2013). In the NEA, the interannual variability of winter ML depth is shown to be largely associated with convective mixing, primarily driven by the fall-wintertime integrated buoyancy loss, mainly due to the heat loss, from the ocean. We showed that this mechanism produces in the SDC layer highly compensated water masses at the base of the ML, hence spice injection. ML interannual variability also drives the entrainment of the water masses because a deeper (shallower) ML mixes the surface water with deeper (shallower) water masses that increase (decrease) spiciness anomalies in the permanent pycnocline. In the NEA, the interannual modulation of ML depth and spice injection results from the interannual variability of the atmospheric winter conditions. The consequent subsurface climate related signals, as also other tracers such as biogeochemical tracers or carbon dioxide (Jenkins 1998), will be sequestrated and advected in the permanent pycnocline (Luyten et al. 1983; Woods 1985; Zhang et al. 2003; Laurian et al. 2006) and within the Madeira Mode Water (Käse et al. 1985; Siedler et al. 1987).

However, hypotheses used in the simple 1D model are very strong and not valid everywhere. Notorious discrepancies between observed and modeled profiles are observed, as seen in 2008 and 2010 (Figs. 14b,e and 14g,j). First, although Weller et al. (2004) have noted that the eddy contribution to the surface heat and salt balance in the subtropical frontal region $\left(34^{\circ} \mathrm{N}\right)$ could be intermittently important, the 1D ML model does not 


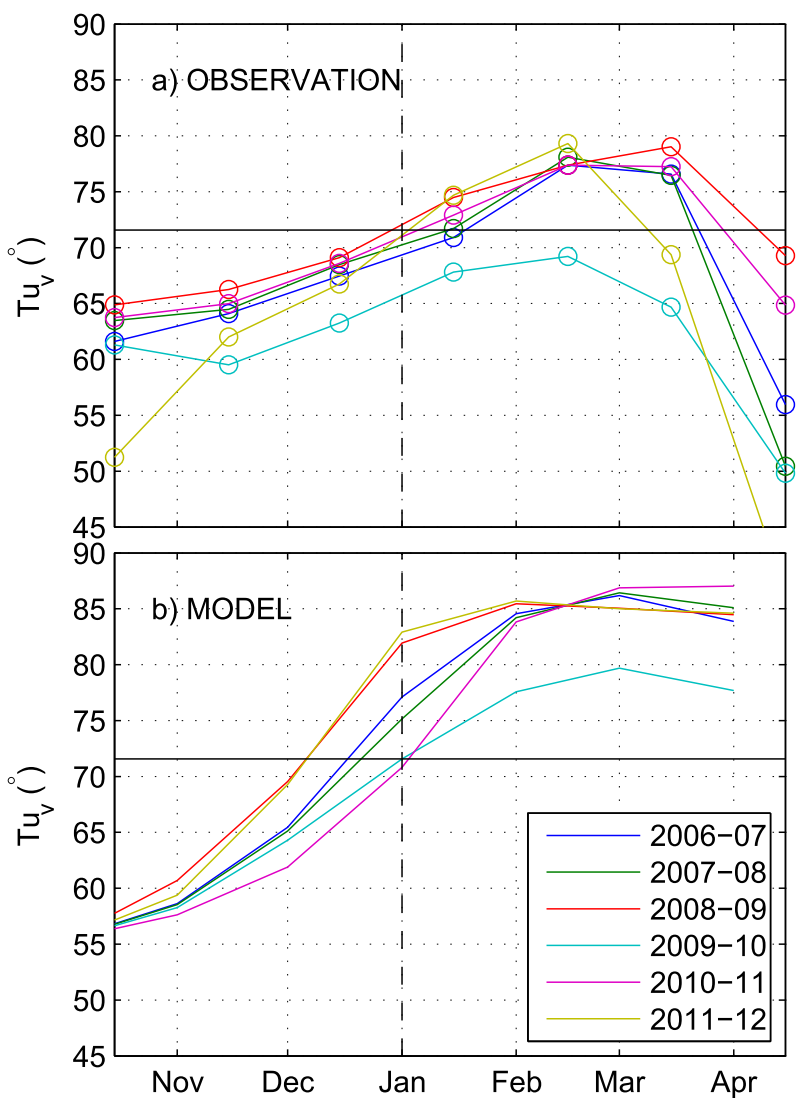

FIG. 12. (a) Evolution of the vertical Turner angle at the base of the mixed layer for the fall-winter periods between 2006 and 2007 observed by Argo profiles within $25^{\circ}-30^{\circ} \mathrm{N}, 30^{\circ}-20^{\circ} \mathrm{W}$ in the NEA region. (b) As in (a), but for the Turner angle corresponding to the thermohaline step in the 1D model.

take into account horizontal advection and mixing terms. A numerical study in that region indicates that this contribution was not dominant in comparison with the heat flux contribution (Caniaux and Planton 1998). The 1D model may capture the main physics for the winter NEA, a region with relatively weak currents and horizontal eddy kinetic energy.

It is also worth noticing that submesoscale variability, including the upward convection and individual convective plumes (few kilometers; Haine and Marshall 1998; Marshall and Schott 1999) are not resolved both in the dataset and the simulation. Furthermore, the subduction can also be controlled by wind stress at submesoscale scale (Hosegood et al. 2013). The development of submesoscale filaments leads to intrusion and transformation of water masses from the ML toward the interior ocean. Furthermore, wind-driven submesoscale subduction happens as well as submesoscale restratification by mixed layer eddies that play an important role in limiting the depth of the mixed layer and penetration of heat at the subsurface (Boccaletti et al. 2007; Fox-Kemper et al. 2008;
Fox-Kemper and Ferrari 2008). These processes, not taken into account in our simple model and missed by the Argo array resolution, could impact the subduction/injection and the water mass transformation (Hosegood et al. 2013). The intensive, highly resolved observations carried out within the Salinity Processes in the Upper Ocean Regional Study (SPURS) area during dedicated cruises in 2012/13 [SPURS, Subtropical North Atlantic Salinity Experiment (STRASSE), and Medidas en Microondas y Desarrollo de Algoritmos para la Misión SMOS (MIDAS)] could be later used to investigate such features in the North Atlantic subtropical region (Busecke et al. 2014).

The 1D model sensitivity is mainly and strongly dependent on the heat and freshwater flux used. Here, the ERA-Interim fluxes have been chosen to force the 1D ML model. The alternate use of the NCEP, OAFLUXTMI, and TROPFLUX-EXT forcing datasets does not qualitatively change the seasonal and interannual results of the 1D ML model, but substantially impacts the quantitative results of the SDC layer formation and spice injection.

The contribution of the vertical shear of horizontal currents has also been neglected in the TKE balance (Niiler and Kraus 1977). If this hypothesis remains valid in the NEA region, it becomes unrealistic in the Gulf Stream region.

Northward of about $20^{\circ} \mathrm{N}$, this study suggests that buoyancy flux is the main driver of ML depth. In this region during the fall-winter (October-March), the weak effect of TKE generated by the wind stress results from relatively weak surface winds and the deep ML.

The shortwave radiative fluxes are also unlikely to penetrate significantly deeper than 60-100-m depth, even in the region of clear water in the subtropical gyres (Sverdrup et al. 1942; Foster 1971; Morel and Antoine 1994; Sweeney et al. 2005) and thus would not significantly contribute to heat the water masses below the ML base. Furthermore, the ERA-Interim products do not take into account the probable effects of Saharan aerosols that contribute to reducing solar input in the ocean (Foltz et al. 2013).

Although a zero thickness SDC layer at the base of the ML as assumed in the 1D model simulation is not observed, it is shown that the idealistic thermohaline step at the mixed layer base is able to capture the physics of the SDC layer: (i) a higher level of vertical compensation with vertical Turner angle greater than $\mathrm{Tu}_{v}=75^{\circ}-80^{\circ}$ in March, and (ii) injection of thermohaline anomalies at the base of the mixed layer (Yeager and Large 2007; Kolodziejczyk and Gaillard 2012). However, during winter the SDC layer is also characterized by a vertical Turner angle generally greater than $\mathrm{Tu}_{v}=71.6^{\circ}$ and is thus double-diffusely unstable (Turner 1973), which is not 

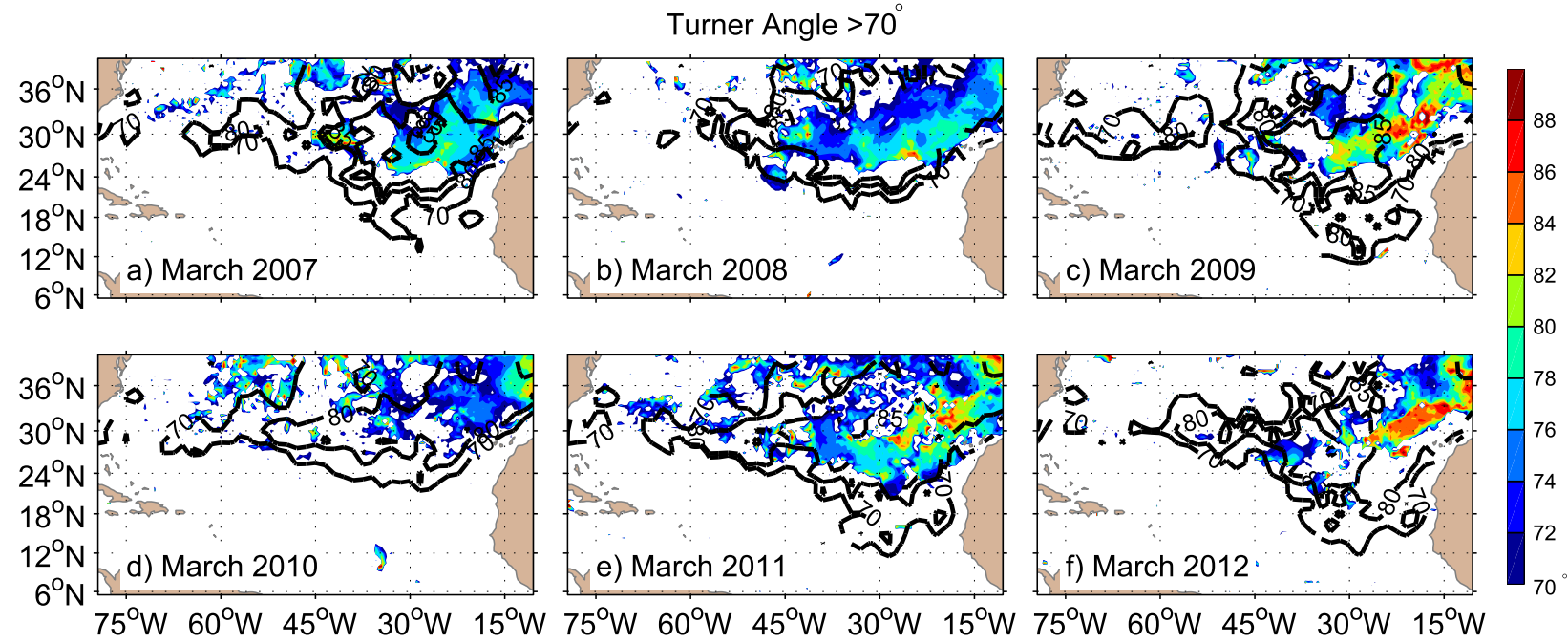

FIG. 13. Vertical Turner angle $\left({ }^{\circ}\right.$; for $\left.\mathrm{Tu}_{v}>70^{\circ}\right)$ at the base of the ML in March from ISAS analysis (color shading) and from 1D model (black contours) between 2007 and 2012.

simulated by this model. In the southeastern subtropical Pacific, Johnson (2006) has shown that vertical mixing simulated using an ad hoc double-diffusion parameterization efficiently erodes the spice signature injected during the late winter. This probably explains why the vertical Turner angle and spiciness signal produced by the 1D model simulation are too large. Moreover, the dynamics below the mixed layer-the Ekman pumping and horizontal advection-within the pycnocline are not represented in the model. These processes are also able to remove spiciness and thermohaline contrast from the mixed layer base (Weller et al. 2004).

Weller et al. (2004) used different models to investigate the 1D ML dynamics in the NEA Atlantic during the subduction experiment. The model they retained is the Price-Weller-Pinkel (PWP; Price et al. 1986), which is equivalent to the Niiler and Kraus (1977) model with diurnal cycle hypotheses, but an explicit parameterization of the vertical mixing at the ML base, and the Mellor and Yamada (1982) model for oceanic boundary layer. They found weak model dependency on their results.

In spite of these caveats, the bulk formulation of the Niiler and Kraus (1977) 1D model including both temperature and salinity used in this study includes in a simple way the main mechanisms controlling the winter ML in the NEA. It simulates to a reasonable extent the amplitude and the year-to-year observed winter ML, SDC layers, and spice injection variability. At large length scales and seasonal time scales, winter convection is likely to dominate the mixed layer response to atmospheric buoyancy forcing and modulates the footprint of climate variability in the permanent pycnocline and mode water layers.
During boreal winter 2010, unusual weak buoyancy loss is reported in the NEA. It is because of a weaker than usual latent heat loss explained by lower than usual trade winds in the NEA region. During winter 2010, the historical record of the NAO index reveals the lowest values reported since 1948 (Fig. 15). The negative NAO index indicates that the Iceland low and Azores high were weakly active. It explains the lower trade winds in the NEA region and the southward shift of the Azores high during winter 2010. The interannual variability of the Azores high may have a broader impact on the water mass subduction in the north subtropical-tropical Atlantic, as well as in the Gulf Stream region as suggested in Figs. 13d and 14g and in Maze et al. (2009), but also over the whole North Atlantic upper ocean (Buchan et al. 2014). It is also noticeable that the strong 2010 winter events, characterized by a historically low NAO index and high TNA index in the tropical Atlantic, coincides with the reversal of the strongest El Niño/La Niña event of the 2000s (2009/10; Figs. 15a,b). This suggests a probable winter teleconnection between the Pacific El Niño event and SST anomalies of the same sign in the tropical North Atlantic (Giannini et al. 2001) and the NAO negative index affecting the subtropical North Atlantic ( $\mathrm{Li}$ and Lau 2012).

In contrast, during boreal winter 2009 and 2012, stronger trade winds produce larger latent cooling and buoyancy loss in the NEA. Convective mixing is more intense and ML deeper. Thus, surface warm and salty waters are mixed with cooler and fresher waters at a deeper level within a heavier range of isopycnals, hence inducing spiciness injection on surfaces that are less often reached by mixed layer properties. This 


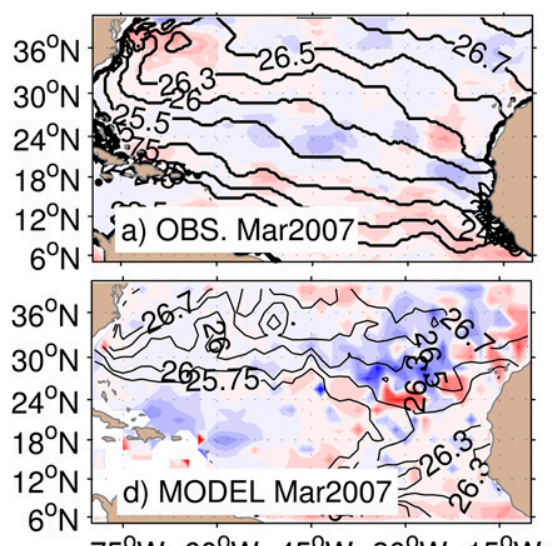

$75^{\circ} \mathrm{W} 60^{\circ} \mathrm{W} 45^{\circ} \mathrm{W} 30^{\circ} \mathrm{W} 15^{\circ} \mathrm{W}$
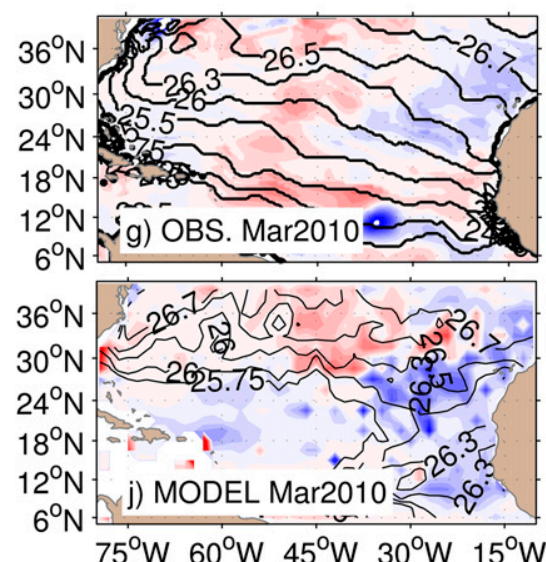
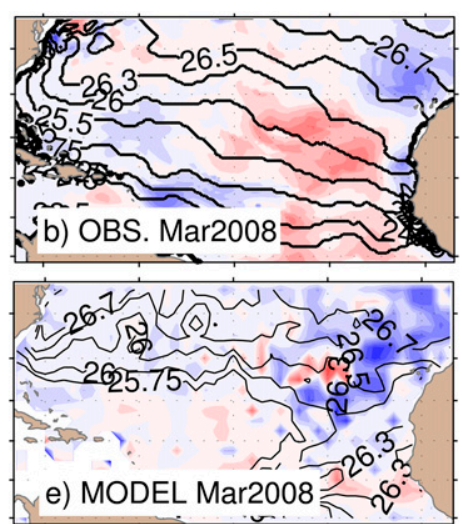

$75^{\circ} \mathrm{W} 60^{\circ} \mathrm{W} 45^{\circ} \mathrm{W} 30^{\circ} \mathrm{W} 15^{\circ} \mathrm{W}$
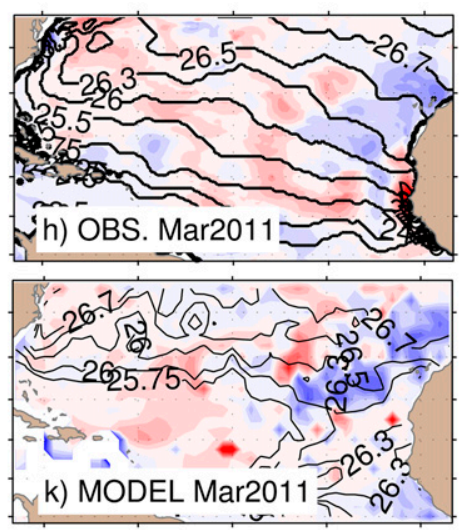
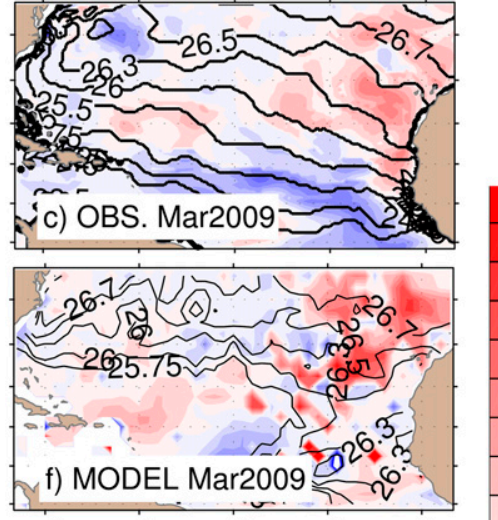

$75^{\circ} \mathrm{W} 60^{\circ} \mathrm{W} 45^{\circ} \mathrm{W} 30^{\circ} \mathrm{W} 15^{\circ} \mathrm{W}$
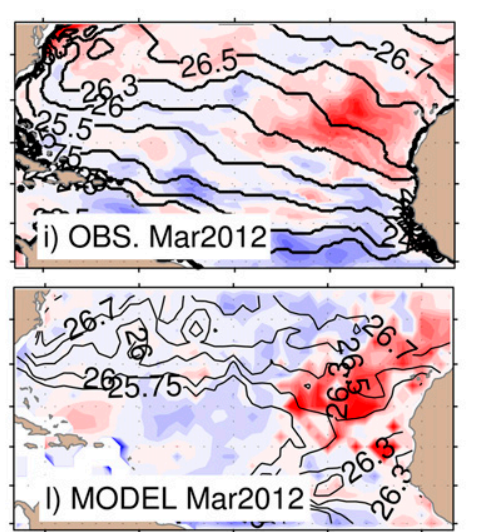

FIG. 14. Spiciness anomalies (pss) computed at the base of the deepest mixed layer in March from (a)-(c),(g)-(i) the ISAS analysis and from (d)-(f),(j)-(l) the 1D model between 2007 and 2012. Density surfaces are contoured in black $\left(\mathrm{kg} \mathrm{m}^{-3}\right)$.

results in a positive spiciness anomaly on these isopycnals. The winters 2009 and 2012 are characterized by a rather negative SST in the tropical Atlantic preceded by a La Niña event in the eastern Pacific (Fig. 15; Giannini et al. 2001). During winter 2012, the North Atlantic weather regime has been associated with the positive phase of the NAO and the so-called Atlantic Ridge weather regime, favoring enhanced wind over the subtropical Atlantic (Hakkinen et al. 2011; Barrier et al. 2013) and important latent heat loss in the NEA.

In the subtropical North Atlantic SSS maximum, the SPURS/STRASSE (http://spurs.jpl.nasa.gov) experiment has been recently dedicated to the observation of the fine structure and subseasonal-to-seasonal variability of SSS. The present study provides large-scale and interannual context of the ocean state for the focused observation of the SPURS experiment. For example, during the Spanish MIDAS cruise in March-April 2013 (http://cp34-bec.cmima.csic.es/the-spurs-midas-cruise/), larger than usual pycnocline salinity was found from CTD casts in the region located southeastward of the
NEA. The high salinity injection and subduction during winter 2012 and the slow advection velocity within the pycnocline (Weller et al. 2004) in this region are likely to explain these subsurface conditions in the SSS maxima (Busecke et al.2014). Because they could have a delayed preconditioning impact on the oceanic upper layer, the large-scale process of water mass transformation and winter subduction in the subtropical North Atlantic thus deserve further study.

Acknowledgments. Nicolas Kolodziejczyk is supported by CNES (French Space Agency) postdoctoral grant. This work is supported by CNES and Laboratoire d'Océanographie: Expérimentation et Approches Numériques (LOCEAN)-Institut Pierre Simon Laplace (IPSL) (CNRS/IRD/UPMC/MNHN, Paris, France), TOSCA SMOS-SOS project. The ERA-Interim reanalysis products are provided by European Centre for Medium-Range Weather Forecasts. The NCEP reanalysis-derived data was provided by the NOAA/ OAR/ESRL PSD, Boulder, Colorado, from their website (www.esrl.noaa.gov/psd/). The global ocean heat flux and 

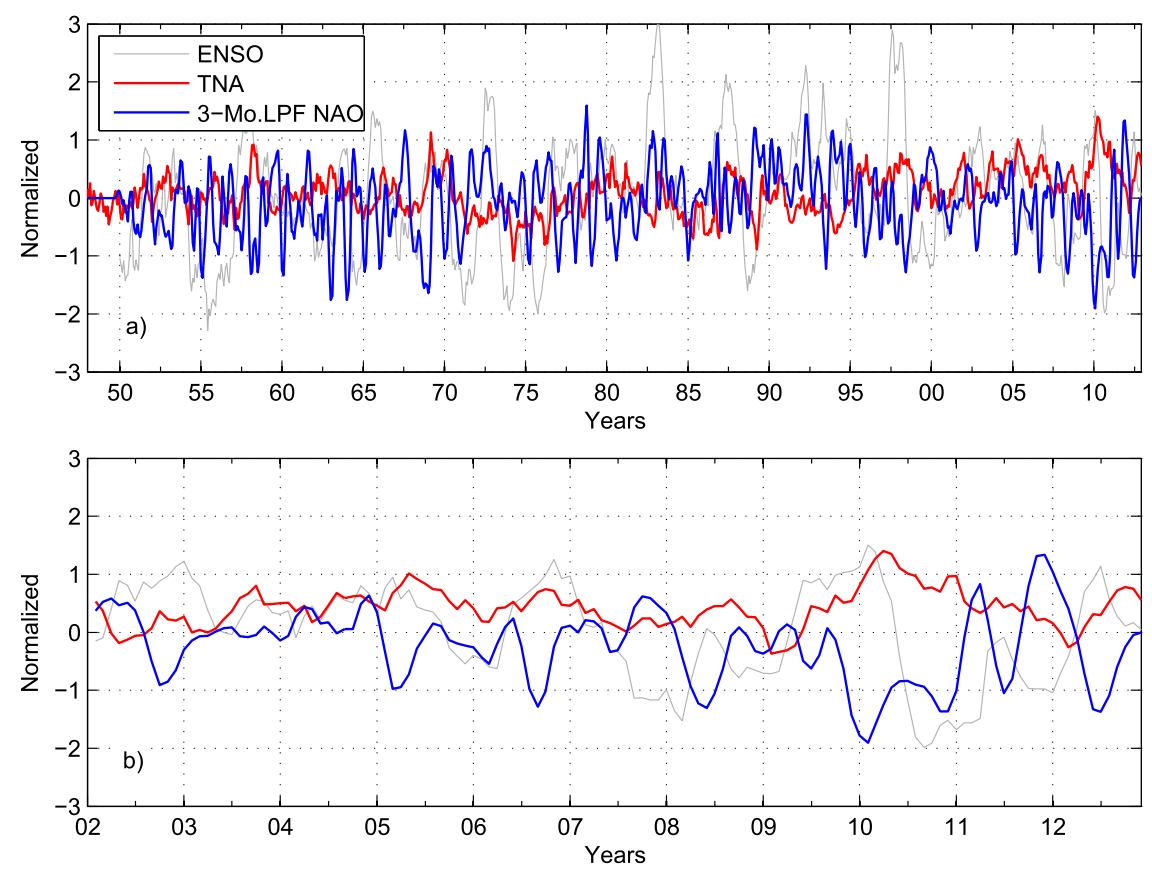

FIG. 15. El Niño-Southern Oscillation (ENSO) multivariate ENSO index (gray), tropical North Atlantic (TNA) index (red), and 3-month low-pass filtered NAO index (blue) over the period (a) 1948-2012 and (b) 2002-12. The $x$-axis labels indicate only the last two digits of the year.

evaporation products (OAFlux) were provided by the WHOI OAFlux project (http://oaflux.whoi.edu) funded by the NOAA Climate Observations and Monitoring (COM) program. The TMI data are produced by Remote Sensing Systems and sponsored by the NASA Earth Science MEaSUREs DISCOVER Project. (Data are available at www.remss.com.) In situ datasets were provided by the Coriolis data center (www.coriolis.eu.org/). The TropFlux data are produced under a collaboration between LOCEAN from IPSL (Paris, France) and National Institute of Oceanography/CSIR (NIO, Goa, India) and supported by Institut de Recherche pour le Développement (IRD, France). TropFlux relies on data provided by the ECMWF Re-Analysis Interim (ERA-I) and ISCCP projects. The authors wish to thank Dr. Fabienne Gaillard for providing validated Argo data and ISAS product. The authors wish to thank anonymous reviewers that contributed to substantially improve the manuscript.

\section{APPENDIX}

\section{D Model Setup and Integration}

\section{a. Mass, salt, and heat conservations}

The heat, salt, and mass conservation equation can be written as

$$
\begin{aligned}
\frac{D T}{D t} & =\frac{Q_{0}}{\rho_{0} C_{p}}, \\
\frac{D S}{D t} & =2 \operatorname{SSS} \frac{(E-P)}{\rho_{0}} \delta(z), \quad \text { and } \\
\frac{D b}{D t} & =B_{0} .
\end{aligned}
$$

The potential temperature is $T ; Q_{0}=\partial Q_{\text {flux }} / \partial z$ is the heat forcing, the divergence of the flux $Q_{\text {flux }}$ being the sum of penetrative solar radiation, longwave radiation, and latent and sensible heat flux; $C_{p}$ is the heat capacity of the seawater; SSS is the sea surface salinity; and $E-P$ is the evaporation minus precipitation flux. Following the formalism of Turner and Kraus (1967), the Dirac delta function $\delta(z)$ expresses the fact that these processes are concentrated at the surface. Its integral is $\int_{-h}^{0} \delta(z) d z=1 / 2$, and $B_{0}=\partial B_{\text {flux }} / \partial z$ is the buoyancy forcing, the divergence of the flux $B_{\text {flux }}$ being defined as

$$
B_{0}=\alpha g \frac{Q_{0}}{\rho_{0} C_{p}}-2 \beta g S S S \frac{E-P}{\rho_{0}} \delta(z) .
$$

The heat and freshwater forcing are constructed from the monthly $0.75^{\circ} \times 0.75^{\circ}$ ERA-Interim (or $1.5^{\circ} \times 1.5^{\circ}$ NCEP) interpolated at each grid point at each time step 
of integration. Note that in this framework the buoyancy flux is taken positive toward the atmosphere.

In the case of a weak horizontal contrast of potential temperature and salinity and weak surface horizontal flow (Fig. 4f), the advective terms from Eqs. (A1) can be neglected. Between $t_{0}$ (at the beginning) and $t_{1}$ (the end) of the vertical state, the conservation of heat, salt, and mass over the near-surface water column implies

$$
\begin{gathered}
T_{S} h-\int_{-h}^{0} T(z) d z=-\int_{t_{0}}^{t_{1}} \rho_{0} C_{p} d t, \\
S_{S} h-\int_{-h}^{0} S(z) d z=\int_{t_{0}}^{t_{1}} \operatorname{SSS}(E-P) d t \\
b_{S} h-\int_{-h}^{0} b(z) d z=-\int_{t_{0}}^{t_{1}} B_{0} d t .
\end{gathered}
$$

These equations represent the redistribution of the temperature, salinity, and buoyancy over the depth of the mixed layer under loss of buoyancy between $t_{0}$ and $t_{1}$.

The mixed layer buoyancy must be equal to the mean of the buoyancy that existed in the layer between $z=0$ and $z=-h$ before mixing (Fig. 3; dotted profile) minus the time integral of the surface buoyancy flux $B_{0}$. Introducing Eq. (4) for the temperature, salinity, and buoyancy in Eqs. (A3a), (A3b), and (A3c), respectively, results in

$$
\begin{aligned}
& \Delta S=\frac{1}{h}\left[\frac{N_{S}^{2}}{2 g \beta}\left(h^{2}-h_{i}^{2}\right)+h_{i} \Delta S_{i}+\int_{t_{0}}^{t_{1}} S(E-P) d t\right], \\
& \Delta T=\frac{1}{h}\left[\frac{N_{T}^{2}}{2} \frac{\left(h^{2}-h_{i}^{2}\right)}{g \alpha}+h_{i} \Delta T_{i}-\int_{t_{0}}^{t_{1}} \frac{Q}{\rho_{0} C_{p}} d t\right], \quad \text { and }
\end{aligned}
$$

$$
\Delta b=\frac{1}{h}\left[\frac{N^{2}}{2}\left(h^{2}-h_{i}^{2}\right)+h_{i} \Delta b_{i}-\int_{t_{0}}^{t_{1}} B_{0} d t\right],
$$

where $\Delta S=S_{s}-S_{h}$ is the difference between ML salinity $S_{s}$ and the salinity $S_{h}$, that is, the salinity step at the base of the ML; $\Delta T=T_{s}-T_{h}$ is the difference between ML temperature $T_{s}$ and the temperature $T_{h}$, that is, the temperature step at the base of the ML; and $\Delta b=b_{s}-b_{h}$ is the difference between ML buoyancy $b_{s}$ and the buoyancy $b_{h}$, that is, the buoyancy step at the base of the ML (Fig. 3). Note that Eq. (A4c) could be written as a function of Eqs. (A4a) and (A4b) using Eq. (1). These expressions are dependent on ML depth, the initial values of the thermohaline step at the base of the ML, the stratification and thermohaline vertical distribution below the ML, and the atmospheric fluxes. In the NEA region,

$$
\begin{aligned}
& N_{b}^{2}=\frac{-g}{\rho_{0}} \frac{\partial \rho}{\partial z}, \\
& N_{S}^{2}=g \beta \frac{\partial S}{\partial z}, \quad \text { and } \\
& N_{T}^{2}=g \alpha \frac{\partial T}{\partial z},
\end{aligned}
$$

where $N_{S}^{2}>0$ indicates that the salinity vertical gradient below the ML base is destabilizing. One shall note that Eq. (1) implies

$$
N_{b}^{2}=N_{T}^{2}-N_{S}^{2}
$$

\section{b. ML depth and TKE equation}

ML depth is obtained injecting the expression (A4c) into Eq. (7) and solving numerically the nonlinear differential equation

$$
\frac{d h}{d t}=\frac{n h B_{0}}{\frac{N^{2}}{2}\left(h^{2}-h_{i}^{2}\right)+h_{i} \Delta b_{i}-\int_{t_{0}}^{t_{1}} B_{0} d t} .
$$

The solution $h\left[B_{0}(x, y, t), h_{i}(x, y), \Delta b_{i}(x, y)\right]$ is mainly sensitive to the winter buoyancy flux, but also to the initial buoyancy profile. Reinjecting $h$ in Eqs. (A4a), (A4b), and (A4c) provides the evolution of the density, salinity, and temperature step at the base of the ML during boreal winter.

The model has been initialized with the mean conditions in October over the period 2006-12. The mean mixed layer depth, thermohaline step values, and permanent pycnocline stratification have been computed from Argo individual profiles and interpolated on the $0.75^{\circ} \times 0.75^{\circ}$ ERA-Interim (or $\left.1.5^{\circ} \times 1.5^{\circ} \mathrm{NCEP}\right)$ grid. The mean value of mixed layer depth has been taken at each grid point as the depth of maximum vertical density gradient. During October, it corresponds to the depth of the mixed layer base (see Figs. 2a,c). The density step $\Delta b$ at the ML base is computed at each grid point as

$$
\Delta b=\int_{0}^{z_{N 2}=5 \times 10^{-5}} \frac{\partial b}{\partial z} d z,
$$

where $z_{N^{2}}=5 \times 10^{-5}$ is the depth at which the stratification becomes smaller than $N^{2}=5 \times 10^{-5} \mathrm{~s}^{-2}$. Below this depth the stratification is assumed to be constant. The temperature step is computed using the same method, and then a salinity step value is deduced using Eq. (1) in order to satisfy the equation of state. The constant stratification 
in the permanent pycnocline is estimated using a vertical mean temperature gradient, salinity gradient, and BruntVäisälä frequency between 100- and 250-m depths during October. These values have been chosen in order to best fit the 1D ML model with observations (Figs. 2, 3).

To obtain the time evolution of ML depth given by the 1D model, Eq. (A7) is numerically integrated at each grid point using an Euler scheme with a 7.4 h (0.01 month) time step from 1 October to April. To deduce the time evolution of the thermohaline step at the ML base, the ML depth is then incorporated to Eq. (A7). The factor $n$ in Eq. (A7), the fraction of buoyancy flux that is effectively converted into potential energy at the base of the mixed layer, is often chosen to be $n=0.2$ in studies on convective mixing (e.g., Caughey 1982; Moeng and Wyngaard 1984; Yeager and Large 2007) and thus a reasonable but probably upper-bound value. Deardorff et al. (1969) found $n=$ 0.015 carrying out the laboratory tank experiment, while Farmer (1975), observing the deepening of the ML under the ice of a frozen lake, found values between $n=0.003$ and $n=0.113$ with a mean of $n=0.036$ for his series of 12 observations. The value $n=0.1$ will be used in this study. As done for the flux products (Fig. 10), sensitivity tests on the modeled mixed layer depth in March in the region $25^{\circ}$ $30^{\circ} \mathrm{N}, 30^{\circ}-20^{\circ} \mathrm{W}$ has been performed, changing the value $n$ from 0.05 to 0.15 . The resulting differences are small compared to the interannual variability of ML depth $(\delta n=$ 0.05 produces $\delta$ MLD $\sim 8 \mathrm{~m}$ ).

Finally, following (de Boyer Montégut et al. 2004) the ML depth criterion chosen on the individual profiles is $\delta \rho=0.03 \mathrm{~kg} \mathrm{~m}^{-3}$. A similar criterion on the ISAS analysis underestimates the ML depth by about $30 \%-35 \%$. The more appropriate criterion on the temperature, $\delta T=$ $0.5^{\circ} \mathrm{C}$, has been chosen to compute the ML depth from the ISAS interpolated fields. This criterion provides a comparable ML depth between individual profiles and interpolated fields (not shown). Note that except for the mapping of the observed ML depth in Fig. 9, the ML depth has been computed from the individual profiles.

\section{REFERENCES}

Ball, F. K., 1960: Controlling inversion height by surface heating. Quart. J. Roy. Meteor. Soc., 86, 483-494, doi:10.1002/qj.49708637005.

Barrier, N., A.-M. Treguier, C. Cassou, and J. Deshayes, 2013: Impact of the winter North-Atlantic weather regimes on subtropical sea-surface height variability. Climate Dyn., 41, 1159-1171, doi:10.1007/s00382-012-1578-7.

Boccaletti, G., R. Ferrari, and B. Fox-Kemper, 2007: Mixed layer instability and restratification. J. Phys. Oceanogr., 37, 22282250, doi:10.1175/JPO3101.1.

Buchan, J., J. J.-M. Hirshi, A. T. Blaker, and B. Sinha, 2014: North Atlantic SST anomalies and cold north European weather events of winter 2009/10 and December 2010. Mon. Wea. Rev., 142, 922-932, doi:10.1175/MWR-D-13-00104.1.
Busecke, J., A. L. Gordon, Z. Li, F. M. Bingham, and J. Font, 2014: Subtropical surface layer salinity budget and the role of mesoscale turbulence. J. Geophys. Res. Oceans, 119, 4124-4140, doi:10.1002/2013JC009715.

Caniaux, G., and S. Planton, 1998: A three-dimensional ocean mesoscale simulation using data from the SEMAPHORE experiment: Mixed layer heat budget. J. Geophys. Res., 103, 25 081-25 099, doi:10.1029/98JC00452.

Caughey, S. J., 1982: Observed characteristics of the atmospheric boundary layer. Atmospheric Turbulence and Air Pollution Modelling, F. T. M. Nieuwstadt and H. van Dop, Eds., Springer, 107-158, doi:10.1007/978-94-010-9112-1_4.

Deardorff, J. W., G. E. Willis, and D. K. Lilly, 1969: Laboratory investigation of non-steady penetrative convection. J. Fluid Mech., 35, 7-31, doi:10.1017/S0022112069000942.

de Boyer Montégut, C., G. Madec, A. S. Fischer, A. Lazar, and D. Iudicone, 2004: Mixed layer depth over the global ocean: An examination of profile data and a profile-based climatology. J. Geophys. Res., 109, C12003, doi:10.1029/2004JC002378.

Doney, S. C., S. Yeager, G. Danabasoglu, W. G. Large, and J. C. McWilliams, 2007: Mechanisms governing interannual variability of the upper-ocean temperature in a global ocean hindcast simulation. J. Phys. Oceanogr., 37, 1918-1938, doi:10.1175/ JPO3089.1.

Farmer, D. M., 1975: Penetrative convection in the absence of mean shear. Quart. J. Roy. Meteor. Soc., 101, 869-891, doi:10.1002/ qj.49710143011.

Ferrari, R., and D. L. Rudnick, 2000: Thermohaline variability in the upper ocean. J. Geophys. Res., 105, 16857-16883, doi:10.1029/ 2000JC900057.

- and F. Paparella, 2003: Compensation and alignment of the thermohaline gradient in the ocean mixed layer. J. Phys. Oceanogr., 33, 2214-2223, doi:10.1175/1520-0485(2003)033<2214: CAAOTG $>2.0 . \mathrm{CO} ; 2$.

Flament, P., 2002: A state variable for characterizing water masses and their diffusive stability: Spiciness. Prog. Oceanogr., 54, 493-501, doi:10.1016/S0079-6611(02)00065-4.

Foltz, G. R., A. T. Evan, H. P. Freitag, S. Brown, and M. J. McPhaden, 2013: Dust accumulation biases in PIRATA shortwave radiation records. J. Atmos. Oceanic Technol., 30, 1414-1432, doi:10.1175/JTECH-D-12-00169.1.

Foster, T. D., 1971: A convective model for diurnal cycle in the upper ocean. J. Geophys. Res., 76, 666-675, doi:10.1029/ JC076i003p00666.

Fox-Kemper, B., and R. Ferrari, 2008: Parameterization of the mixed layer eddies. Part I: Prognostic and impact. J. Phys. Oceanogr., 38, 1166-1179, doi:10.1175/2007JPO3788.1.

,-- , and R. Halberg, 2008: Parameterization of the mixed layer eddies. Part I: Theory and diagnosis. J. Phys. Oceanogr., 38, 1145-1165, doi:10.1175/2007JPO3792.1.

Gaillard, F., E. Autret, V. Thierry, P. Galaup, C. Coatanoan, and T. Loubrieu, 2009: Quality control of large Argo datasets. J. Atmos. Oceanic Technol., 26, 337-351, doi:10.1175/2008JTECHO552.1.

Giannini, A., J. C. H. Chiang, M. A. Cane, Y. Kushnir, and R. Seager, 2001: The ENSO teleconnection to the tropical Atlantic Ocean: Contributions of the remote and local SSTs to rainfall variability in the tropical Americas. J. Climate, 14, 4530-4544, doi:10.1175/ 1520-0442(2001)014<4530:TETTTT>2.0.CO;2.

Gu, D., and S. G. H. Philander, 1997: Interdecadal climate fluctuations that depend on exchanges between the tropics and extratropics. Science, 275, 805-807, doi:10.1126/ science.275.5301.805. 
Haine, T. W. N., and J. Marshall, 1998: Gravitational, symmetric and baroclinic instability of the ocean mixed layer. J. Phys. Oceanogr., 28, 634-658, doi:10.1175/1520-0485(1998)028<0634: $\mathrm{GSABIO}>2.0 . \mathrm{CO} ; 2$.

Hakkinen, S., P. B. Rhines, and D. L. Worthen, 2011: Warm and saline events embedded in the meridional circulation of the northern North Atlantic. J. Geophys. Res., 116, C03006, doi:10.1029/ 2010JC006275.

Hanawa, K., and L. D. Talley, 2001: Mode waters. Ocean Circulation and Climate, Academic Press, 373-386.

Hautala, S. L., and D. H. Roemmich, 1998: Subtropical Mode Water in the northeast Pacific basin. J. Geophys. Res., 103, 13 055-13 066, doi:10.1029/98JC01015.

Hosegood, P. J., M. C. Gregg, and M. H. Alford, 2013: Wind-driven submesoscale subduction at the North Pacific Subtropical Front. J. Geophys. Res., 118, 5333-5352, doi:10.1002/jgrc.20385.

Iselin, C. O'D., 1939: The influence of vertical and lateral turbulence on the characterization of waters at mid-depth. Eos, Trans. Amer. Geophys. Union, 20, 414-417, doi:10.1029/TR020i003p00414.

Izumi, Y., 1964: The evolution of temperature and velocity profiles during breakdown of a nocturnal inversion and low-level jet. J. Appl. Meteor., 3, 70-82, doi:10.1175/1520-0450(1964)003<0070: TEOTAV $>2.0 . \mathrm{CO} ; 2$

Jackett, D. R., and T. J. McDougall, 1985: An oceanographic variable for characterization of the intrusions and water masses. Deep-Sea Res., 32, 1195-1207.

Jenkins, W. J., 1998: Studying subtropical thermocline ventilation and circulation using tritium and ${ }^{3} \mathrm{He}$. J. Geophys. Res., 103, 15 817-15 831, doi:10.1029/98JC00141.

Johnson, G. C., 2006: Generation and initial evolution of a mode water $\theta-$ S anomaly. J. Phys. Oceanogr., 36, 739-751, doi:10.1175/ JPO2895.1.

— S. Schimidtko, and J. M. Lyman, 2012: Relative contributions of temperature and salinity to seasonal mixed layer density changes and horizontal density gradients. J. Geophys. Res., 117, C04015, doi:10.1029/2011JC007651.

Käse, R. H., W. Zenk, T. B. Sanford, and W. Hiller, 1985: Current front and eddy flux in the Canary basin. Prog. Oceanogr., 14, 231-251, doi:10.1016/0079-6611(85)90013-8.

Katsura, S., E. Oka, B. Qiu, and N. Schneider, 2013: Formation and subduction of North Pacific Tropical Water and their interannual variability. J. Phys. Oceanogr., 43, 2400-2415, doi:10.1175/JPO-D-13-031.1.

Kolodziejczyk, N., and F. Gaillard, 2012: Interannual variability of spiciness in the Pacific pycnocline. J. Geophys. Res., 117, C12018, doi:10.1029/2012JC008365.

$\longrightarrow$, and - 2013: Variability of the heat and salt budget in the subtropical southeastern Pacific mixed layer between 2004 and 2010: Spice injection mechanism. J. Phys. Oceanogr., 43, 18801898, doi:10.1175/JPO-D-13-04.1.

Kraus, E. B., and J. S. Turner, 1967: A one-dimensional model of the seasonal thermocline. II. The general theory and its consequences. Tellus, 19, 98-106, doi:10.1111/j.2153-3490.1967.tb01462.x.

Laurian, A., A. Lazar, G. Reverdin, K. Rodgers, and P. Terray, 2006: Poleward propagation of spiciness anomalies in the North Atlantic Ocean. Geophys. Res. Lett., 33, L13603, doi:10.1029/ 2006GL026155.

,$- \ldots$, and — 2009: Generation mechanism of spiciness anomalies: An OGCM analysis in the North Atlantic Subtropical Gyre. J. Phys. Oceanogr., 39, 1003-1017, doi:10.1175/ 2008JPO3896.1.

Lazar, A., R. Murtugudde, and A. J. Busalacchi, 2001: A model study of temperature anomaly propagation from subtropics to tropics within the South Atlantic thermocline. Geophys. Res. Lett., 28, 1271-1274, doi:10.1029/2000GL011418.

_, T. Inui, P. Malanotte-Rizzoli, A. J. Busalacchi, L. Wang, and R. Murtugudde, 2002: Seasonality of the ventilation of the tropical Atlantic thermocline in an ocean general circulation model. J. Geophys. Res., 107, doi:10.1029/2000JC000667.

Li, Y., and N. C. Lau, 2012: Impact of ENSO on the atmospheric variability over the North Atlantic in late winter-Role of transient eddies. J. Climate, 25, 320-342, doi:10.1175/ JCLI-D-11-00037.1.

—, F. Wang, and Y. Sun, 2012: Low-frequency spiciness variations in the tropical Pacific Ocean observed during 2003-2012. Geophys. Res. Lett., 39, L23601, doi:10.1029/2012GL053971.

Liu, H., S. A. Grodsky, and J. A. Carton, 2009: Observed seasonal variability of barrier layer and compensated layer. J. Climate, 22, 6104-6119, doi:10.1175/2009JCLI2974.1.

Liu, L. L., and R. X. Huang, 2012: The global subduction/obduction rates: Their interannual and decadal variability. J. Climate, $\mathbf{2 5}$ 1096-1115, doi:10.1175/2011JCLI4228.1.

Liu, Z., and S.-I. Shin, 1999: On the thermocline ventilation of active and passive tracers. Geophys. Res. Lett., 26, 357-360 doi:10.1029/1998GL900315.

Luo, Y., L. M. Rothstein, R.-H. Zhang, and A. J. Busalacchi, 2005: On the connection between South Pacific subtropical spiciness anomalies and decadal equatorial variability in an ocean general circulation model. J. Geophys. Res., 110, C10002, doi:10.1029/ 2004JC002655.

Luyten, J. R., J. Pedlosky, and H. Stommel, 1983: The ventilated thermocline. J. Phys. Oceanogr., 13, 292-309, doi:10.1175/ 1520-0485(1983)013<0292:TVT>2.0.CO;2.

Marshall, J. C., and F. Schott, 1999: Open-ocean convection: Observations, theory and models. Rev. Geophys., 37, 1-64, doi:10.1029/98RG02739.

— A. J. G. Nurser, and R. G. Williams, 1993: Inferring subduction rate and period over the North Atlantic. J. Phys. Oceanogr., 23, 1315-1329, doi:10.1175/1520-0485(1993)023<1315: ITSRAP $>2.0 . \mathrm{CO} ; 2$.

Maze, G., and J. C. Marshall, 2011: Diagnosing the observed seasonal cycle of the Atlantic Subtropical Mode Water using potential vorticity and its attendant theorems. J. Phys. Oceanogr., 41, 1986-1999, doi:10.1175/2011JPO4576.1.

, G. Forget, M. Buckley, J. Marshall, and I. Cerovecki, 2009: Using transformation and formation maps to study the role of air-sea heat fluxes in North Atlantic Eighteen Degree Water formation. J. Phys. Oceanogr., 39, 1818-1835, doi:10.1175/ 2009JPO3985.1.

Mellor, G. L., and T. Yamada, 1982: Development of a turbulence closure model for geophysical fluid problem. Rev. Geophys. 20, 851-875, doi:10.1029/RG020i004p00851.

Moeng, C.-H., and J. C. Wyngaard, 1984: Statistics of conservative scalars in the convective boundary layer. J. Atmos. Sci., 41, 31613169, doi:10.1175/1520-0469(1984)041<3161:SOCSIT >2.0.CO;2.

Morel, A., and D. Antoine, 1994: Heating rate within the upper ocean in relation to its bio-optical state. J. Phys. Oceanogr., 24, 1652-1665, doi:10.1175/1520-0485(1994)024<1652:HRWTUO>2.0.CO;2.

Munk, W., 1981: Internal waves and small-scale processes. Evolution of Physical Oceanography, B. A. Warren and C. Wunsch, Eds., MIT Press, 264-291.

Niiler, P. P., and E. B. Kraus, 1977: One-dimensional models of the upper ocean. Modeling and Prediction of the Upper Layer of the Ocean, E. B. Kraus, Ed., Pergamon, 143-172.

Nonaka, M., and H. Sasaki, 2007: Formation mechanism for isopycnal temperature-salinity anomalies propagating from the 
eastern South Pacific to the equatorial region. J. Climate, 20, 1305-1315, doi:10.1175/JCLI4065.1.

Nurser, A. J. G., and J. C. Marshall, 1991: On the relationship between subduction rates and diabatic forcing of the mixed layer. J. Phys. Oceanogr., 21, 1793-1802, doi:10.1175/ 1520-0485(1991)021<1793:OTRBSR > 2.0.CO;2.

Praveen Kumar, B., J. Vialard, M. Lengaigne, V. S. N. Murty, and M. J. McPhaden, 2012: TropFlux: Air-sea fluxes for the global tropical oceans-Description and evaluation. Climate Dyn., 38, 1521-1543, doi:10.1007/s00382-011-1115-0.

Price, J. F., R. A. Weller, and R. Pinkel, 1986: Diurnal cycling: Observation and models of the upper ocean response to diurnal heating, cooling and wind mixing. J. Geophys. Res., 91, 8411-8427, doi:10.1029/JC091iC07p08411.

Qiu, B., and R. X. Huang, 1995: Ventilation of North Atlantic and North Pacific: Subduction versus obduction. J. Phys. Oceanogr., 25, 2374-2390, doi:10.1175/1520-0485(1995)025<2374: VOTNAA $>2.0 . \mathrm{CO} ; 2$.

Qu, T., S. Gao, and I. Fukumori, 2013: Formation of salinity maximum water and its contribution to the overturning circulation in the North Atlantic as revealed by a global general circulation model. J. Geophys. Res. Oceans, 118, 1982-1994, doi:10.1002/jgrc.20152.

Ren, L., and S. C. Riser, 2010: Observations of decadal time scale salinity change in the subtropical thermocline of the North Pacific Ocean. Deep-Sea Res. II, 57, 1161-1170, doi:10.1016/ j.dsr2.2009.12.005.

Reverdin, G., E. Kestenare, C. Franckignoul, and T. Delcroix, 2007: Surface salinity in the Atlantic Ocean $\left(30^{\circ} \mathrm{S}-50^{\circ} \mathrm{N}\right)$. Prog. Oceanogr., 73, 311-340, doi:10.1016/j.pocean.2006.11.004.

Ruddick, B., 1983: A practical indicator of the stability of the water column to double-diffusive activity. Deep-Sea Res., 30A, 1105-1107, doi:10.1016/0198-0149(83)90063-8.

Rudnick, D. L., and R. Ferrari, 1999: Compensation of the horizontal temperature and salinity gradient in the ocean mixed layer. Science, 283, 526-529, doi:10.1126/science.283.5401.526. , and J. P. Martin, 2002: On the horizontal density ratio in the upper ocean. Dyn. Atmos. Oceans, 36, 3-21, doi:10.1016/ S0377-0265(02)00022-2.

Sasaki, Y. N., N. Schneider, N. Maximenko, and K. Lebedev, 2010: Observational evidence for propagation of decadal spiciness anomalies in the North Pacific. Geophys. Res. Lett., 37, L07708, doi:10.1029/2010GL042716.

Schmitt, R. W., 1999: Spice and the demon. Science, 283, 498-499, doi:10.1126/science.283.5401.498.

Schneider, N., 2000: A decadal spiciness mode in the tropics. Geophys. Res. Lett., 27, 257-260, doi:10.1029/1999GL002348.

_ 2004: The response of the tropical climate to the equatorial emergence of spiciness anomaly. J. Climate, 17, 1083-1095, doi:10.1175/1520-0442(2004)017<1083:TROTCT>2.0.CO;2.

_ , A. J. Miller, M. A. Alexander, and C. Deser, 1999: Subduction of decadal North Pacific temperature anomalies: Observations and dynamics. J. Phys. Oceanogr., 29, 1056-1070, doi:10.1175/ 1520-0485(1999)029<1056:SODNPT>2.0.CO;2.

Siedler, G., A. Kuhl, and W. Zenk, 1987: The Madeira Mode Water. J. Phys. Oceanogr., 17, 1561-1570, doi:10.1175/ 1520-0485(1987)017<1561:TMMW>2.0.CO;2.

St. Laurent, L., and R. W. Schmitt, 1999: The contribution of salt fingers to vertical mixing in the North Atlantic tracer release experiment. J. Phys. Oceanogr., 29, 1404-1424, doi:10.1175/ 1520-0485(1999)029<1404:TCOSFT>2.0.CO;2.

Stommel, H. M., 1979: Determination of water mass properties of water pumped down from Ekman layer to the geostrophic flow below. Proc. Natl. Acad. Sci. USA, 76, 3051-3055, doi:10.1073/ pnas.76.7.3051.

_ 1993: A conjectural regulating mechanism for determining the thermohaline structure in the ocean mixed layer. J. Phys. Oceanogr., 23, 142-148, doi:10.1175/1520-0485(1993)023<0142: ACRMFD $>2.0 . C O ; 2$.

Sverdrup, H. U., M. W. Johnson, and R. H. Fleming, 1942: The Oceans. Prentice Hall, 1087 pp.

Sweeney, C., A. Gnanadesikan, S. M. Griffies, M. J. Harrison, A. J. Rosati, and B. L. Samuel, 2005: Impacts of shortwave penetration depth on large-scale ocean circulation and heat transport. J. Phys. Oceanogr., 35, 1103-1119, doi:10.1175/ JPO2740.1.

Tailleux, R., A. Lazar, and C. J. C. Reason, 2005: Physical and dynamics of density-compensated temperature and salinity anomalies. Part I: Theory. J. Phys. Oceanogr., 35, 849-864, doi:10.1175/JPO2706.1.

Turner, J. S., 1973: Buoyancy Effects in Fluids. Cambridge University Press, $367 \mathrm{pp}$. , and E. B. Kraus, 1967: A one-dimensional model of the seasonal thermocline. I. A laboratory experiment and its interpretation. Tellus, 19, 88-97, doi:10.1111/j.2153-3490.1967.tb01461.x.

Veronis, G., 1972: On properties of seawater defined by temperature, salinity and pressure. J. Mar. Res., 30, 227-255.

Weller, R. A., P. W. Furey, M. A. Spall, and R. E. Davis, 2004: The large-scale context for oceanic subduction in the northeast Atlantic. Deep-Sea Res. I, 51, 665-699, doi:10.1016/ j.dsr.2004.01.003.

Woods, J. D., 1985: Physics of the thermocline ventilation. Coupled Atmosphere Ocean Model, J. C. J. Nihoul, Ed., Elsevier Oceanography Series, Vol. 40, Elsevier, 543-590, doi:10.1016/ S0422-9894(08)70730-X.

Yeager, G. S., and W. G. Large, 2004: Late-winter generation of spiciness on subducted isopycnals. J. Phys. Oceanogr., 34, 1528-1546, doi:10.1175/1520-0485(2004)034<1528: LGOSOS $>2.0$. CO;2.

$\longrightarrow$, and - 2007: Observational evidence of winter spice injection. J. Phys. Oceanogr., 37, 2895-2019, doi:10.1175/ 2007JPO3629.1.

Yu, L. S., X. Jin, and R. A. Weller, 2008: Multidecade global flux datasets from the Objectively Analyzed Air-Sea Fluxes (OA-Flux) project: Latent heat and sensible heat fluxes, ocean evaporation, and related surface meteorological variables. Woods Hole Oceanographic Institution OAFlux Project Tech. Rep. OA-2008-01, 64 pp. [Available online at http://oaflux.whoi.edu/pdfs/OAFlux_TechReport_3rd_release. pdf.]

Zhang, D., M. J. McPhaden, and W. E. Johns, 2003: Observational evidence for flow between the subtropical and tropical Atlantic: The Atlantic subtropical cells. J. Phys. Oceanogr., 33, 1783-1797, doi:10.1175/2408.1.

Zhang, Y., W. B. Rossow, A. A. Lacis, V. Oinas, and M. I. Mishchenko, 2004: Calculation of radiative fluxes from the surface to top of atmosphere based on ISCCP and other global data sets: Refinements of the radiative transfer model and the input data. J. Geophys. Res., 109, D19105, doi:10.1029/2003JD004457. 